Article

\title{
Comparative Analysis of Complete Chloroplast Genome Sequences of Wild and Cultivated Bougainvillea (Nyctaginaceae)
}

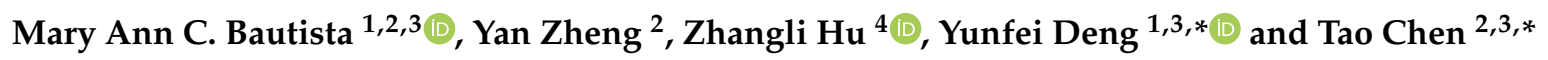 \\ 1 South China Botanical Garden, Chinese Academy of Sciences, Guangzhou 510650, China; \\ bautista.maryann@gmail.com \\ 2 Fairy Lake Botanical Garden, Chinese Academy of Sciences, Shenzhen 518004, China; yanzheng@szbg.ac.cn \\ 3 Graduate School, University of Chinese Academy of Sciences, Beijing 100049, China \\ 4 School of Life Sciences and Oceanology, Shenzhen University, Shenzhen 518060, China; huzl@szu.edu.cn \\ * Correspondence: yfdeng@scbg.ac.cn (Y.D.); taochen@szbg.ac.cn (T.C.); Tel.: +86-20-2725-2677 (Y.D.); \\ $+86-755-2582-5277$ (T.C.)
}

Received: 27 October 2020; Accepted: 26 November 2020; Published: 28 November 2020

check for updates

\begin{abstract}
Bougainvillea (Nyctaginaceae) is a popular ornamental plant group primarily grown for its striking colorful bracts. However, despite its established horticultural value, limited genomic resources and molecular studies have been reported for this genus. Thus, to address this existing gap, complete chloroplast genomes of four species (Bougainvillea glabra, Bougainvillea peruviana, Bougainvillea pachyphylla, Bougainvillea praecox) and one Bougainvillea cultivar were sequenced and characterized. The Bougainvillea cp genomes range from 153,966 bp to 154,541 bp in length, comprising a large single-copy region $(85,159 \mathrm{bp}-85,708 \mathrm{bp})$ and a small single-copy region $(18,014 \mathrm{bp}-18,078 \mathrm{bp})$ separated by a pair of inverted repeats $(25,377-25,427 \mathrm{bp})$. All sequenced plastomes have 131 annotated genes, including 86 protein-coding, eight rRNA, and 37 tRNA genes. These five newly sequenced Bougainvillea $\mathrm{cp}$ genomes were compared to the Bougainvillea spectabilis $\mathrm{cp}$ genome deposited in GeBank. The results showed that all cp genomes have highly similar structures, contents, and organization. They all exhibit quadripartite structures and all have the same numbers of genes and introns. Codon usage, RNA editing sites, and repeat analyses also revealed highly similar results for the six cp genomes. The amino acid leucine has the highest proportion and almost all favored synonymous codons have either an A or U ending. Likewise, out of the 42 predicted RNA sites, most conversions were from serine $(\mathrm{S})$ to leucine $(\mathrm{L})$. The majority of the simple sequence repeats detected were $\mathrm{A} / \mathrm{T}$ mononucleotides, making the $\mathrm{cp}$ genomes $\mathrm{A} / \mathrm{T}-\mathrm{rich}$. The contractions and expansions of the IR boundaries were very minimal as well, hence contributing very little to the differences in genome size. In addition, sequence variation analyses showed that Bougainvillea $\mathrm{cp}$ genomes share nearly identical genomic profiles though several potential barcodes, such as $y c f 1, n d h \mathrm{~F}$, and $r p o \mathrm{~A}$ were identified. Higher variation was observed in both B. peruviana and B. pachyphylla $\mathrm{cp}$ sequences based on SNPs and indels analysis. Phylogenetic reconstructions further showed that these two species appear to be the basal taxa of Bougainvillea. The rarely cultivated and wild species of Bougainvillea (B. pachyphylla, B. peruviana, B. praecox) diverged earlier than the commonly cultivated species and cultivar (B. spectabilis, B. glabra, B. cv.). Overall, the results of this study provide additional genetic resources that can aid in further phylogenetic and evolutionary studies in Bougainvillea. Moreover, genetic information from this study is potentially useful in identifying Bougainvillea species and cultivars, which is essential for both taxonomic and plant breeding studies.
\end{abstract}

Keywords: Bougainvillea; Nyctaginaceae; chloroplast genome; phylogeny 


\section{Introduction}

The family Nyctaginaceae, distributed primarily in the tropics and subtropics, contains around 400 species of trees, shrubs, and herbs classified in ca. 31 genera [1,2]. Nyctaginaceae has been well-recognized as one of the core groups of Caryophyllales (Centrospermae) based on the presence of betalain pigments, free-central placentation, p-type sieve tube elements, perisperm, and molecular evidence [1,3]. One of the most popular genera in Nyctaginaceae is Bougainvillea, a tropical and subtropical shrubby vine cultivated primarily for its colorful showy bracts. Their vibrant structures often mistaken as "flowers" are actually bracts or specialized leaves (ca. 0.5-2-inch long), in which the true flowers are attached at the mid-rib [4]. The true perfect flowers are normally small, tubular, white or yellowish in color, and surrounded by colorful petaloid bracts [4]. Due to Bougainvillea's growth habit and attractive bracts, it became a widely known plant for landscaping [4]. It is commonly used in gardens as hedges or barriers, topiaries, and as ground cover on banks.

The horticulturally important species, such as Bougainvillea glabra and Bougainvillea spectabilis, are native to South America, but were brought and introduced to various countries all over the world. There are approximately 18 species of Bougainvillea, but only the above two species are well-known for cultivation $[1,5]$. The purpose of planting Bougainvillea is mostly ornamental, but recently a number of studies have explored the potential use of Bougainvillea as a medicinal plant and as a pollution-mitigating plant in industrial areas [6-11]. Recent research studies have tapped into the potential of Bougainvillea as an anti-inflammatory, anticancer, antioxidant, antimicrobial, and antihyperglycemic plant [7-11]. Specifically, Bougainvillea spectabilis has been well-known for its ability to lower blood sugar and improve liver function, while Bougainvillea cv. buttiana and Bougainvillea glabra exhibit significant anti-inflammatory activities $[7,9,10]$. The plant group has garnered research attention from the horticultural and pharmaceutical industries, and even in environmental studies. However, no recent studies have focused on the taxonomy of Bougainvillea, particularly regarding the wild species not utilized for cultivation.

Most of the publications on Bougainvillea focused on taxonomic descriptions were published decades ago [12-14], and no actual revision of the topic has been attempted since then. Molecular studies based on short-fragment sequences centered on Nyctaginaceae include only a few sequences of Bougainvillea. Phylogenetic studies on family Nyctaginaceae based on $n d h \mathrm{~F}, r p s 16, r p l 16$, and nrITS revealed that Bougainvillea glabra and Bougainvillea infesta are actually closely related to Belemia and Phaeoptilum [15]. Similarly, the phylogenomic study about the order Caryophyllales includes only Bougainvillea spectabilis as representative of Bougainvilleeae [16]. To date, no phylogenetic study has been published focusing specifically on Bougainvillea species.

Even though next generation sequencing (NGS) has instigated a rapid increase in the available complete organelle genome sequences of plants that can be used for phylogenetic studies, sequences of Bougainvillea are rarely deposited in the database. The commercial value of Bougainvillea as an ornamental plant has overshadowed the need for genetic studies. Hence, the majority of the available sequences in the GenBank are from the commercially cultivated Bougainvillea. Short-genome announcement papers have presented the gene content and structure of B. glabra and B. spectabilis [17,18]. It was also shown that Bougainvillea is clustered together with Acleisanthes, Mirabilis, and Nyctaginia; however, specific relationships cannot be inferred due to the lack of available sequences [17]. Currently, there is very little information available on the genetic structures of Bougainvillea, particularly on their plastome features and specific phylogenetic placements.

It has been established that plastomes, particularly chloroplast genomes, are useful in phylogenetic studies due to their ability to self-replicate, their conservative structure, and their slow evolutionary rate [19]. Investigating the genome organization and genetic information for plastid genomes provide scientists relevant data that can be utilized for species conservation, phylogenetic reconstruction, molecular marker development, genomic evolution studies, and for solving taxonomic complexities in different taxa [19-21]. Therefore, sequencing additional cp genomes of Bougainvillea species is an initial step that is needed to fill the gap in genomic resources before conducting further studies. Thus, 
this study aimed to characterize the cp genome sequences of several cultivated and wild Bougainvillea species (Bougainvillea glabra, Bougainvillea peruviana, Bougainvillea pachyphylla, Bougainvillea praecox, and Bougainvillea cv.). Specifically, the study aimed to discuss the structures and features of the five newly sequenced cp genomes, including the codon usage, RNA editing, simple sequence repeats, tandem repeats, IR contractions and expansion, divergent regions, SNPs, and indels. Phylogenetic analyses were also conducted to determine the relationship among cultivated and wild Bougainvillea in the family Nyctaginaceae.

\section{Results and Discussion}

\subsection{General Features of Bougainvillea Chloroplast Genomes}

The assembled chloroplast genome sequences of Bougainvillea glabra, Bougainvillea peruviana, Bougainvillea pachyphylla, Bougainvillea praecox, and Bougainvillea cv., together with the available sequence of Bougainvillea spectabilis, range from 153,966 bp to 154,541 bp. Similar to most sequenced Nyctaginaceae cp genomes, they all exhibit the typical quadripartite structure, consisting of a large single-copy (LSC) region (85,159-85,708 bp), a small single-copy (SSC) region (18,014-18,078 bp), and a pair of inverted repeats $(25,377-25,427 \mathrm{bp})$ (Figure 1, Table 1). The commonly cultivated Bougainvillea spectabilis and Bougainvillea glabra have the largest cp genomes, but despite the differences in size, all cp genomes have a total of 131 genes, including 86 protein-coding genes, eight rRNA, and 37 tRNA. Of the identified genes, there are seven protein-coding ( $n d h \mathrm{~B}, r p l 2, r p l 23, r p s 7, r p s 12, y c f 1, y c f 2)$, four rRNA ( $r r n 4.5, r r n 5, r r n 16, r r n 23)$, and seven tRNA (trnI-CAU, $t r n$ L-CAA, $t r n$ V-GAC, $t r n \mathrm{I}-\mathrm{GAU}, t r n \mathrm{~A}-\mathrm{UGC}$, trnR-ACG, trnN-GUU) genes duplicated in the IR regions. Thus, there are 79 unique protein-coding genes that function primarily in photosynthesis and transcription-translation processes, while the remaining are transfer RNA genes (30), and ribosomal RNA genes (four) (Table 2). The numbers of rRNA and tRNA genes are highly conserved among Nyctaginaceae, but the number of protein-coding genes differs due to acetyl-CoA carboxylase subunit $\mathrm{D}$ gene $(a c \mathrm{D})$ loss in some genera. Bougainvillea cp genomes have an intact accD gene, whereas Nycataginia capitata (MH286318.1) and Pisonia aculeata (MK397866.1) lack the accD gene. In general, the genome structure and features of the Bougainvillea cp genomes are highly similar to most Nyctaginaceae chloroplast genomes-no significant changes in the gene order or gene content have been observed.

Table 1. Complete chloroplast genome features of five Bougainvillea species and one cultivar.

\begin{tabular}{|c|c|c|c|c|c|c|}
\hline Features & B. glabra & B. peruviana & B. pachyphylla & B. praecox & B. cultivar & B. spectabilis \\
\hline Genome size (bp) & 154,536 & 153,966 & 154,062 & 154,306 & 154,520 & 154,541 \\
\hline LSC length (bp) & 85,708 & 85,159 & 85,181 & 85,474 & 85,688 & 85,694 \\
\hline SSC length (bp) & 18,038 & 18,025 & 18,027 & 18,014 & 18,078 & 18,077 \\
\hline IR length (bp) & 25,395 & 25,391 & 25,427 & 25,409 & 25,377 & 25,385 \\
\hline Total no. of genes & 131 & 131 & 131 & 131 & 131 & 131 \\
\hline Protein-coding genes & 86 & 86 & 86 & 86 & 86 & 86 \\
\hline rRNA & 8 & 8 & 8 & 8 & 8 & 8 \\
\hline tRNA & 37 & 37 & 37 & 37 & 37 & 37 \\
\hline $\begin{array}{l}\text { Overall GC } \\
\text { content }(\%)\end{array}$ & $36.5 \%$ & $36.6 \%$ & $36.5 \%$ & $36.5 \%$ & $36.5 \%$ & $36.4 \%$ \\
\hline $\begin{array}{l}\text { GC content } \\
\text { in LSC }(\%)\end{array}$ & $34.2 \%$ & $34.3 \%$ & $34.3 \%$ & $34.3 \%$ & $34.2 \%$ & $34.2 \%$ \\
\hline $\begin{array}{l}\text { GC content } \\
\text { in SSC }(\%)\end{array}$ & $29.5 \%$ & $29.6 \%$ & $29.6 \%$ & $29.5 \%$ & $29.5 \%$ & $29.5 \%$ \\
\hline $\begin{array}{c}\text { GC content } \\
\text { in IR }(\%)\end{array}$ & $42.8 \%$ & $42.8 \%$ & $42.8 \%$ & $42.8 \%$ & $42.8 \%$ & $42.7 \%$ \\
\hline
\end{tabular}




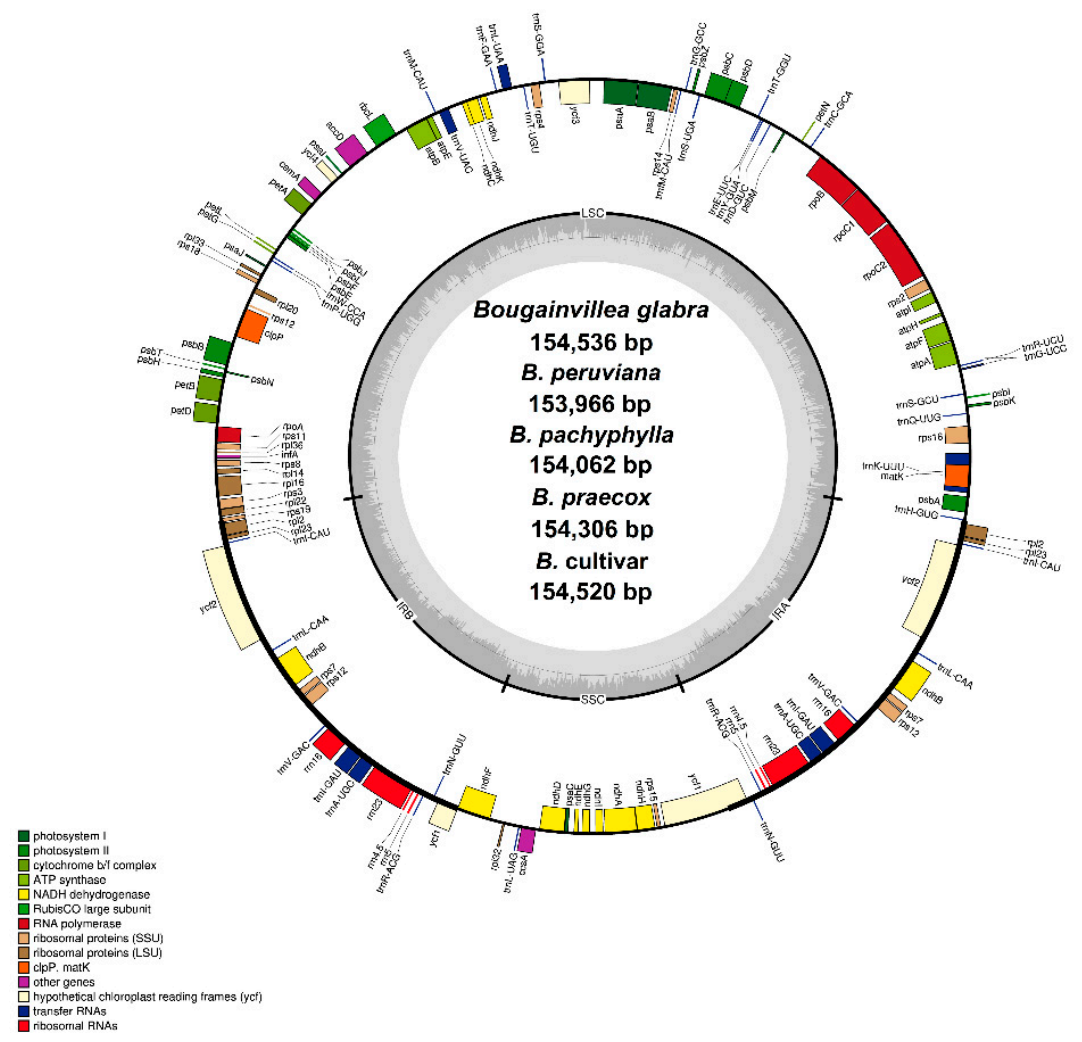

Figure 1. Circular gene map of five newly sequenced Bougainvillea chloroplast genomes. The genes drawn outside the circle are transcribed clockwise, while the genes on the inside are transcribed counterclockwise. Genes belonging to different functional groups are color-coded. The dark gray plot in the inner circle represents the GC (Guanine-Cytosine) content, whereas the light-grey corresponds to the AT (Adenine-Thymine) content.

In addition, there are also 17 intron-containing genes identified in all six cp genomes, of which 15 genes $(r p s 16, a t p \mathrm{~F}, r p o \mathrm{C} 1, p e t \mathrm{~B}, p e t \mathrm{D}, r p l 16, r p l 2, n d h \mathrm{~B}, n d h \mathrm{~A}, \operatorname{trn\mathrm {I}-GAU}, \operatorname{trn} \mathrm{A}-\mathrm{UGC}, t r n \mathrm{~V}-\mathrm{UAC}$, trnL-UAA, trn G-UCC, trnK-UUU) have one intron, while $c l p P$ and $y c f 3$ have two introns each (Table 2). The trnK-UUU gene has the longest intron (2508-2524 bp), which encodes the matK ORF. This is normally perceived in published cp genomes, since plastid trn introns are relatively longer in comparison to nuclear tRNA introns [22]. A trans-splicing event also occurs in the rps 12 gene, with the $5^{\prime}$ exon positioned in the LSC region, while the $3^{\prime}$ exons are duplicated in the IR regions. The aforementioned genes with introns can be categorized into three types-genes for electron transfer, protein synthesis, and ATP synthesis. Most introns in general do not code for proteins, but recent studies have shown that they can enhance gene expression and regulation in specific locations [23,24]; hence, they are potential sites for efficient processing of native or foreign transcripts that can improve particular horticultural traits in plants such as Bougainvillea.

Overall, the GC contents of the six Bougainvillea cp genomes are almost identical, ranging from $36.4 \%$ to $36.6 \%$. Interestingly, the GC contents of the IR regions (42.7-42.8\%) are higher compared to the LSC (34.2-34.3\%) and SSC regions (29.5-29.6\%). Higher GC contents in IR regions are typically linked to the presence of rRNA genes in the IRs or to the GC-biased conversion (gBGC) [20]. The gBGC is a preferential fixation of AT to GC mutations over GC to AT mutations, thus increasing the GC contents in recombination hotspots such as IR regions [25-27]. 
Table 2. List of genes encoded by six Bougainvillea cp genomes.

\begin{tabular}{|c|c|}
\hline Gene Category & Gene Names \\
\hline ATP Synthase & $\operatorname{atp} \mathrm{A}, \operatorname{atp} \mathrm{B}, \operatorname{atp} \mathrm{E}, \operatorname{atp} \mathrm{F}^{*}, \operatorname{atp} \mathrm{H}, \operatorname{atp} \mathrm{I}$ \\
\hline NADH dehydrogenase & $\begin{array}{l}n d h \mathrm{~A}^{*}, n d h \mathrm{~B}^{(\mathrm{X} 2) *}, n d h \mathrm{C}, n d h \mathrm{D}, n d h \mathrm{E}, n d h \mathrm{~F}, n d h \mathrm{G}, n d h \mathrm{H}, n d h \mathrm{I}, \\
n d h \mathrm{~J}, n d h \mathrm{~K}\end{array}$ \\
\hline Cytochrome b/f complex & $\operatorname{pet} \mathrm{A}, \operatorname{pet} \mathrm{B}^{*}, \operatorname{pet} \mathrm{D}^{*}, \operatorname{pet} \mathrm{G}, \operatorname{pet} \mathrm{L}, \operatorname{pet} \mathrm{N}$ \\
\hline Photosystem I & $p s a \mathrm{~A}, p s a \mathrm{~B}, p s a \mathrm{C}, p s a \mathrm{I}, p s a \mathrm{~J}$ \\
\hline Photosystem II & $\begin{array}{l}p s b \mathrm{~A}, p s b \mathrm{~B}, p s b \mathrm{C}, p s b \mathrm{D}, p s b \mathrm{E}, p s b \mathrm{~F}, p s b \mathrm{H}, p s b \mathrm{I}, p s b \mathrm{~J}, p s b \mathrm{~K}, p s b \mathrm{~L}, \\
p s b \mathrm{M}, p s b \mathrm{~N}, p s b \mathrm{~T}, p s b \mathrm{Z}\end{array}$ \\
\hline RubisCO large subunit & $r b c \mathrm{~L}$ \\
\hline Ribosomal protein genes (large subunits) & $r p l 2^{(\times 2) *}, r p l 14, r p l 16^{*}, r p l 20, r p l 22, r p l 23^{(\mathrm{x} 2)}, r p l 32, r p 133, r p l 36$ \\
\hline Ribosomal protein genes (small subunits) & $\begin{array}{l}r p s 2, r p s 3, r p s 4, r p s 7^{(\mathrm{x} 2)}, r p s 8, r p s 11, r p s 12^{(\mathrm{x} 2) \#}, r p s 14, r p s 15, \\
r p s 16^{*}, r p s 18, r p s 19\end{array}$ \\
\hline RNA Polymerase & $r p o \mathrm{~A}, r p o \mathrm{~B}, r p o \mathrm{C} 1 *, r p o \mathrm{C} 2$ \\
\hline Ribosomal RNA genes & $r r n 4.5^{(\mathrm{X} 2)}, r r n 5^{(\mathrm{X} 2)}, r r n 16^{(\mathrm{X} 2)}, r r n 23^{(\mathrm{X} 2)}$ \\
\hline Transfer RNA genes & 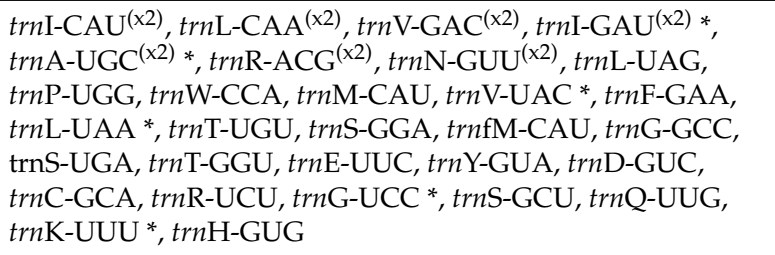 \\
\hline ATP-dependent protease & $\operatorname{clpP} \mathrm{P}^{* *}$ \\
\hline Maturase & matK \\
\hline Hypothetical chloroplast reading frames & $y c f 1^{(x 2)}, y c f 2^{(x 2)}, y c f 3^{* *}, y c f 4$ \\
\hline Acetyl-CoA carboxylase & $\operatorname{acc} \mathrm{D}$ \\
\hline C-type cytochrome synthesis gene & $\operatorname{ccs} \mathrm{A}$ \\
\hline Envelope membrane protein & $\operatorname{cem} \mathrm{A}$ \\
\hline Translational initiation factor & $\inf \mathrm{A}$ \\
\hline
\end{tabular}

\subsection{Codon Usage Analysis}

Approximately $48-52 \%$ of the six Bougainvillea cp genomes are comprised of protein-coding genes with $24,557-26,717$ codons. Of these codons, leucine (10.50-10.64\%) and isoleucine $(8.67-8.76 \%)$ are the most abundant amino acids, whereas cysteine (1.10-1.15\%) has the lowest frequency (Figure 2). The high leucine frequency can be attributed to the fact that leucine biosynthesis is greatly needed in chloroplasts, due to its important function in photosynthesis-related metabolism [28]. On the other hand, cysteine is quite reactive and considered toxic if it is allowed to accumulate above a certain level [29]. It is also highly susceptible to changes in biological conditions [30]. This pattern is highly uniform in most angiosperm cp genomes [21,31].

In addition, codon usage analysis also revealed that there are particular amino acid codons that are more frequently used or preferred [32]. This codon usage bias has been commonly observed in plant genomes, and it is assumed that preferred codons are normally utilized in highly expressed genes [33]. Based on the relative synonymous codon usage values (RSCU), all amino acid codons found in the six Bougainvillea cp genomes exhibit codon preferences, except for tryptophan (UGG) and methionine (AUG) (RSCU =1). There are 30 codons that are highly favored (RSCU $>1$ ) and 32 codons that are less preferred (RSCU $<1$ ). Moreover, it can be observed that out of the 30 preferred codons, 29 are A/U-ending codons, meaning that C/G-ending codons are less common in the chloroplast genomes. Several reported cp genomes from other families such as Zingiberaceae, Euphorbiaceae, and Asparagaceae have constantly reported the same occurrence $[31,34,35]$. The bias towards high A/U occurrences in the third nucleotide position of codons appears to be conserved among higher plants. 


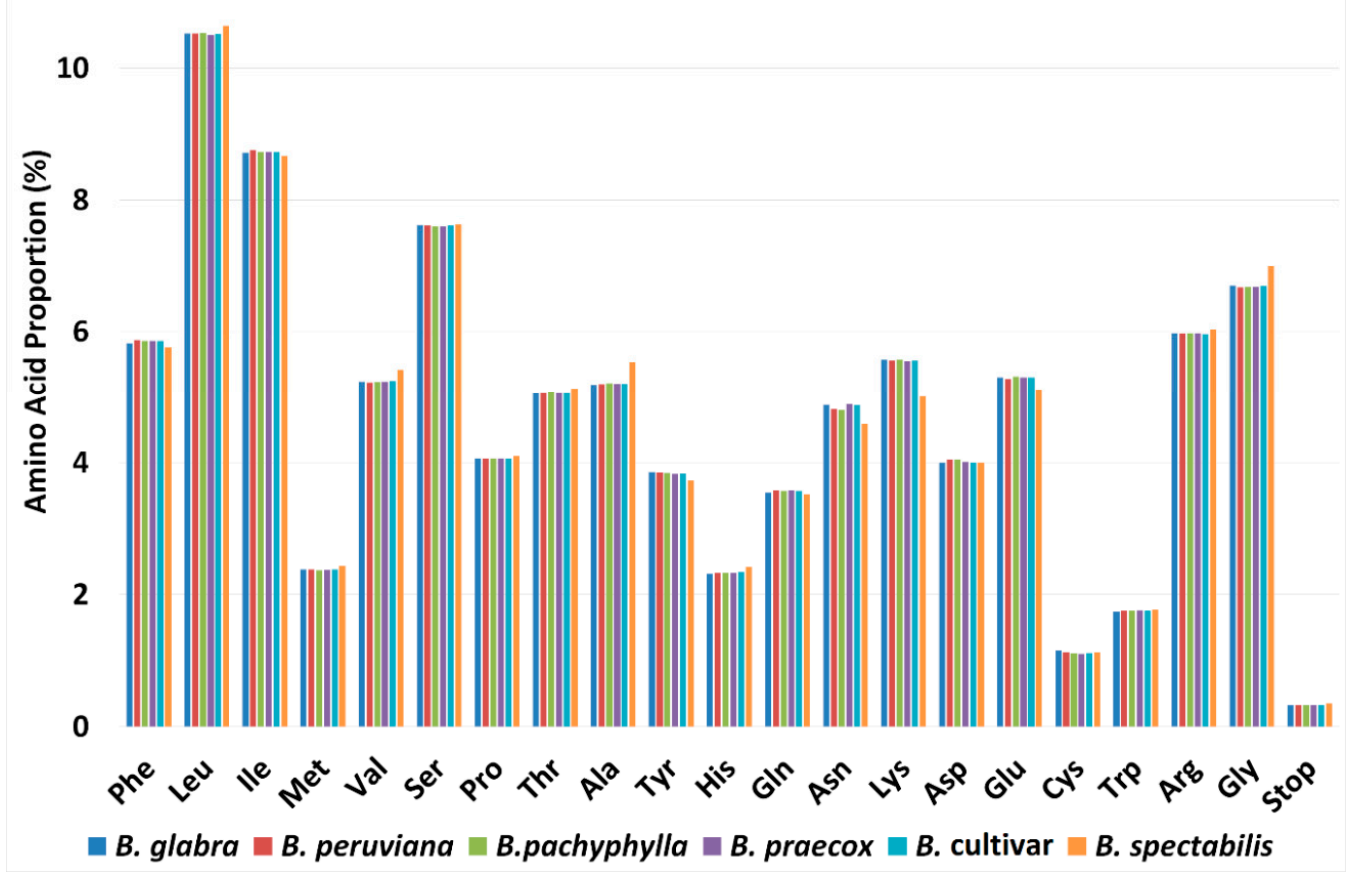

Figure 2. Percentages of amino acid in the protein-coding regions of six Bougainvillea chloroplast genomes.

\subsection{RNA Editing Sites}

Nucleotide sequences in cpDNAs are commonly altered at the transcript level through RNA editing and RNA splicing. Thus, determining the RNA editing sites is necessary in order to understand coding information in the cp genomes. Putative RNA editing sites in the six Bougainvillea cp genomes were predicted using the Predictive RNA Editor for Plants (PREP) software, which identified a total of 42 RNA editing sites. Parallel to other seed plants, the annotated RNA editing sites in the Bougainvillea cp genomes were $\mathrm{C}$ to $\mathrm{U}$ conversions located in the first or second position of the codons (Table S2). C to U editing mainly occurred in chloroplast and mitochondrial genomes of angiosperms and gymnosperms, although $\mathrm{U}$ to $\mathrm{C}$ conversions were also observed in ferns and bryophytes [36]. Consistent with prior studies, most of the editing sites were observed to be distributed mainly in the $n d h$ genes $(n d h \mathrm{~A}, n d h \mathrm{~B}, n d h \mathrm{D}, n d h \mathrm{~F}, n d h \mathrm{G})$ of the cp genomes, particularly in $n d h \mathrm{~B}(12$ sites) [36,37]. In addition, most of the RNA editing amino acids have a tendency to be converted from serine (S) to Leucine (L), and the majority of the changes were from hydrophilic to hydrophobic. These results indicate that RNA editing increases hydrophobicity, which might influence the proteins' secondary or tertiary structures [36,38]. RNA editing can actually lead to re-establishment of conserved amino acid residues, increases in hydrophobicity, and regulation of protein expression [36,38].

\subsection{Simple Sequence Repeats and Tandem Repeat Analyses}

The analysis of repetitive sequences identified a total of $80,83,84,80,89$, and 89 chloroplast simple sequence repeats (cpSSRs) in Bougainvillea glabra, Bougainvillea peruviana, Bougainvillea pachyphylla, Bougainvillea praecox, Bougainvillea cv., and Bougainvillea spectabilis, respectively (Figure 3A-C). Bougainvillea spectabilis and Bougainvillea cv. have the highest numbers of cpSSRs, while Bougainvillea glabra and Bougainvillea praecox have the lowest numbers of cpSSRs. In agreement with other studies, about $71.25-78.3 \%$ of the identified cpSSRs are A/T mononucleotides, and most of the dinucleotides, trinucleotides, tetranucleotides, and pentanucleotides contain $\mathrm{A} / \mathrm{T}$, hence contributing to the AT richness of Bougainvillea cp genomes (Figure 3D). Trinucleotides are rare in Bougainvillea cp genomes-only 
B. glabra has trinucleotides detected in its cp genome. Chloroplast simple sequence repeats are also primarily found in the intergenic spacers of the LSC region (Figure 3A,B). The frequency of cpSSRs in coding regions is relatively lower, since the rate of mutation in cpSSRs is higher and might affect gene expression [39]. As mentioned in earlier studies, cpSSRs in the non-coding regions typically exhibit intraspecies differences in repeat number [40]. SSRs are also considered as a popular chloroplast marker due to their high level of polymorphism, co-dominance mode of inheritance, and multi-allelic nature [41]. Therefore, identified cpSSRs can be potentially useful for population studies or phylogeographic studies of Bougainvillea species and their cultivars. The initial cpSSR study conducted in fifty cultivars of Bougainvillea verified that SSRs can be used for molecular characterization and identification of cultivars [41].
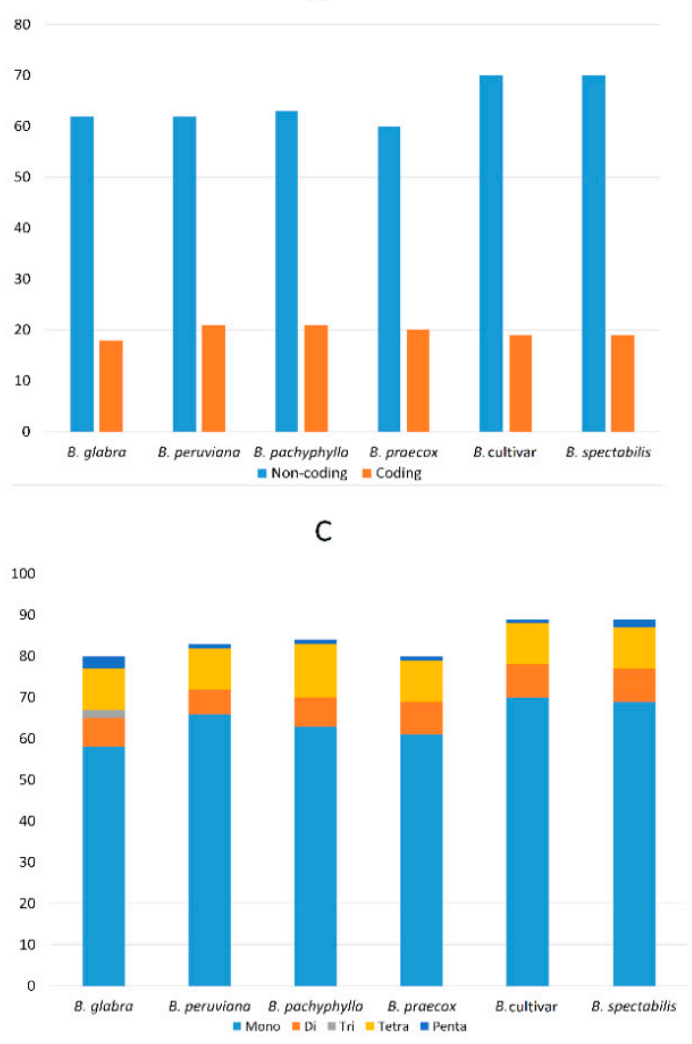

B

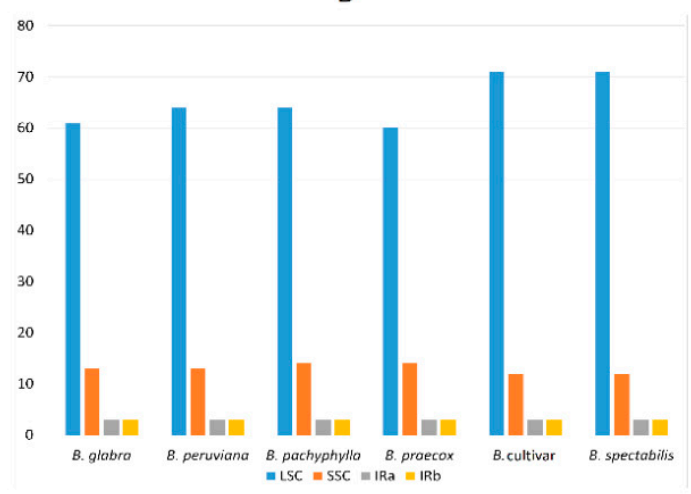

D

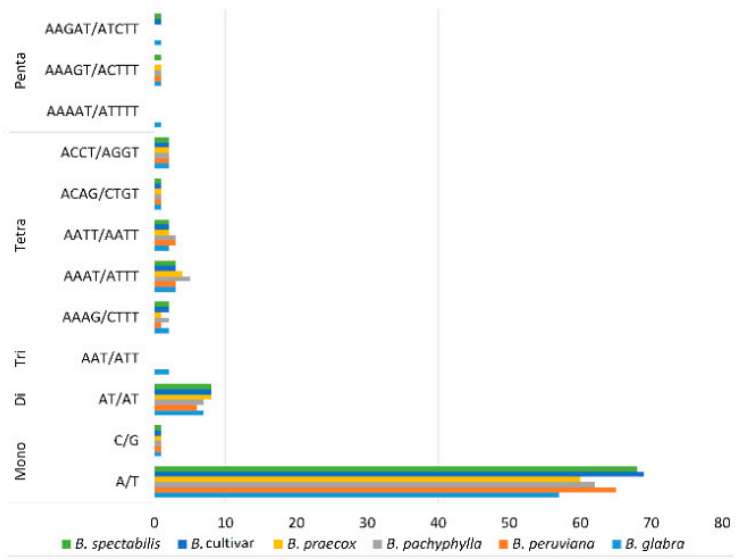

Figure 3. Analysis of simple sequence repeats (SSRs) in six Bougainvillea chloroplast genomes. (A) Simple sequence repeats detected in coding and non-coding regions of six Bougainvillea cp genomes. (B) Simple sequence repeats distributions in the LSC, SSC, and IR regions of Bougainvillea cp genomes. (C) Numbers of different types of SSRs identified in the Bougainvillea cp genomes. (D) Frequency of various SSR types identified in six Bougainvillea cp genomes.

In addition to SSRs, tandem repeats (TRs) were also determined in the six cp genomes using Tandem Repeats Finder v4.04. Bougainvillea glabra (26) has the highest number of identified tandem repeats, whereas Bougainvillea peruviana (17) and Bougainvillea pachyphylla (19) have the lowest. The remaining three (B. praecox, B. spectabilis, B. cultivar) have the same number of tandem repeats. Similar to SSR, TRs in the six cp genomes are mostly distributed in the non-coding areas of the LSC region (Figure $4 \mathrm{~A}, \mathrm{~B})$. The lengths of the identified TRs range from 11 to $32 \mathrm{bp}$, but they are mainly around 15-18 bp (Figure 4C). All TRs found in the coding regions of six genomes are located in the hypothetical chloroplast reading frame $y c f 2$. A higher density of TRs in non-coding regions is quite common in angiosperms, since mutations in TRs situated in the known protein-coding regions can result in protein 
function changes [42]. TR mutations occur due to modifications in the number of repeating units, which can possibly cause unfavorable phenotypes [43].

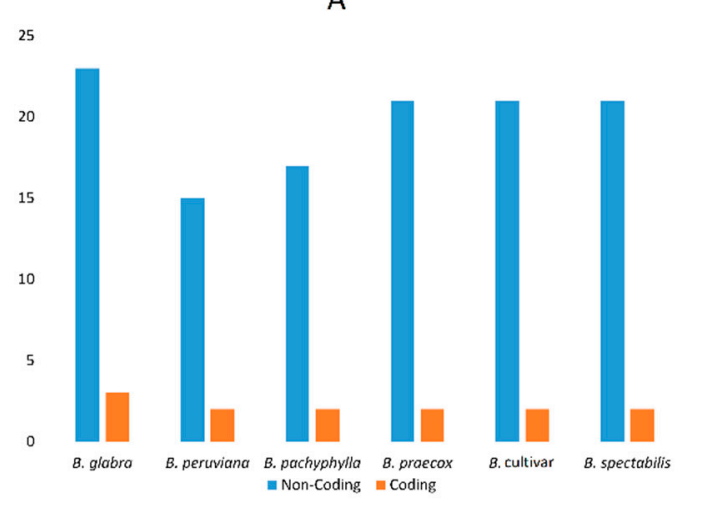

B

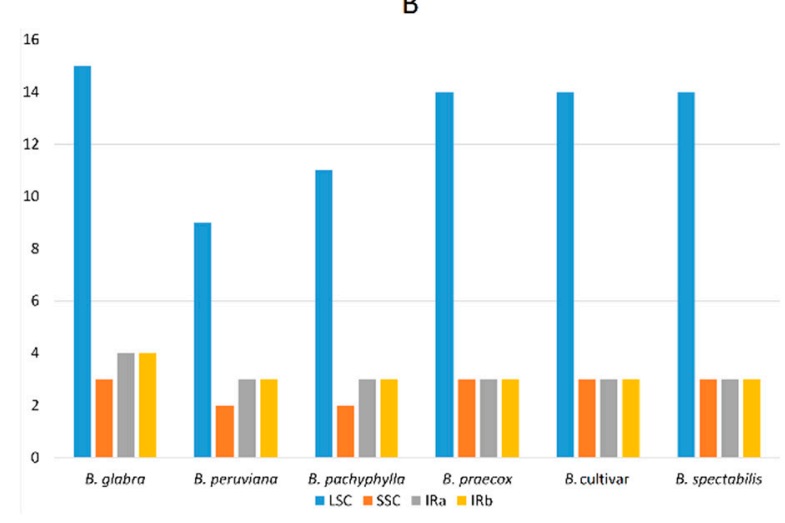

C

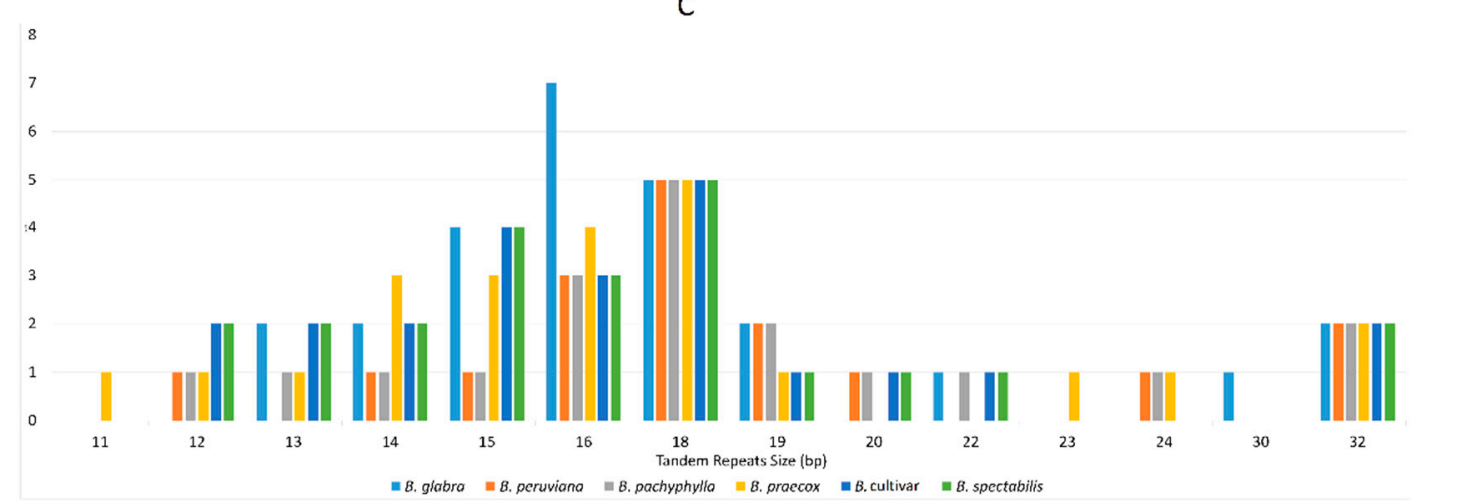

Figure 4. Tandem repeat analysis in six Bougainvillea cp genomes. (A) Frequency of tandem repeats in the non-coding and coding regions of six cp genomes. (B) Distributions of the detected tandem repeats in LSC, SSC, and IR regions. (C) Lengths of the identified tandem repeats in all six Bougainvillea cp genomes.

\subsection{IR Contraction and Expansion}

Inverted repeat regions are generally conserved among land plants. They all contain four rRNA, five tRNA genes, and a few protein-coding genes as a result of some expansion and contraction in the IR junctions [44]. Sequences flanking the IR junctions may vary among different species, which might result in genome size variation. In Bougainvillea cp genomes, the gene contents and arrangements are highly similar, however there are few contractions and expansions in the IR boundaries (Figure 5). For instance, the IRb-LSC junction (JLB) is situated within the rps19 gene in all Bougainvillea cp genomes, thus rps19 has a 114 bp extension in the IRb region. In addition, all taxa have the ycf 1 gene in the IRa-SSC junction (JSA), hence producing long fragments of $y c f 1$ in the IRb-SSC junction (JSB). It is also evident that the partial copies of $y c f 1$ in the IRb regions of all cp genomes overlap with the $n d h \mathrm{~F}$ gene. However, in five Bougainvillea cp genomes (B. glabra, B. peruviana, B. pachyphylla, B. praecox, $B$. cv.), the $y c f 1$ fragments have two bp extension in the IRb-SSC junction (JSB), suggesting an infinitesimal expansion of the IR. This IR contraction and expansion pattern is usually observed in most angiosperms $[31,44,45]$. All of the sequences used in this study belong to the same genus, so the IR boundary shifts are relatively minor, hence contributing very little to the observed differences in genome size. 


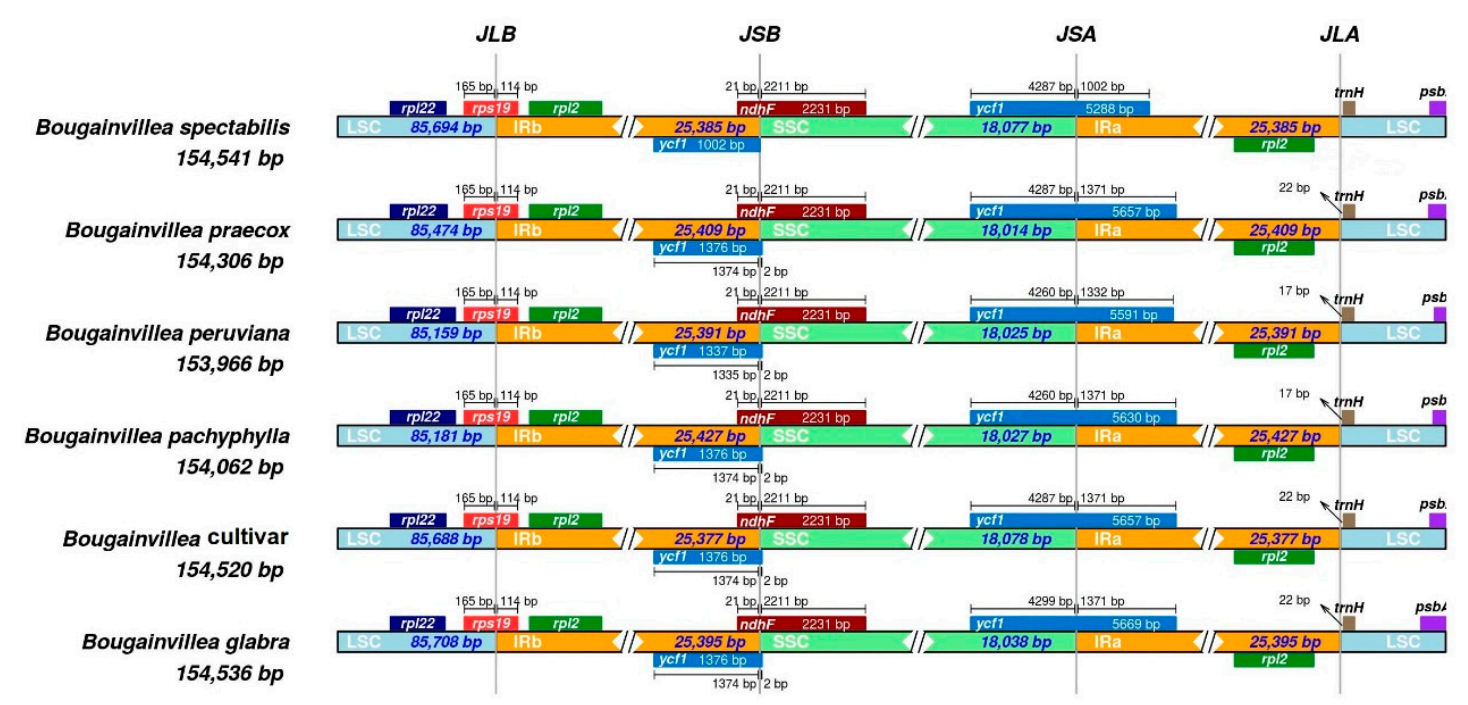

Figure 5. Comparisons of LSC, SSC, and IRs junctions among the six chloroplast genomes.

\subsection{Sequence Variation Analyses among Bougainvillea cp Genomes}

Sequence divergence among Bougainvillea cp genomes was compared through multiple sequence alignment carried out in mVISTA. Generally, no significant rearrangements were observed among Bougainvillea cp genomes, but several regions displayed higher variation than others. Resulting alignment analysis using Bougainvillea glabra as a reference showed that the coding regions of the Bougainvillea cp genomes are less divergent compared to the non-coding regions, whereas the non-coding regions are more variable than the coding regions (Figure 6). Likewise, the IR regions have lower divergence and more conserved compared to LSC and SSC regions. Specifically, protein-coding genes such as $y c f 1$ and $n d h \mathrm{~F}$ and non-coding regions such as start-psbA, rps16-psbK, psbI-atpA, psaA-ycf3, petD-rpo A, and $n d h \mathrm{~F}-r p l 32$ are considered to be highly divergent regions.

To further examine the sequence divergence in the Bougainvillea cp genomes, nucleotide diversity (Pi) values were calculated using DnaSP v5.10 (Figure 7). Similar standards to those employed in the Zingiberaceae family were used to determine the divergence hotspots in coding and non-coding regions [31]. For the 79 unique protein-coding genes, the nucleotide diversity values range from 0 to 0.2282 , with an average of 0.00307 . Eleven protein-coding genes $(p e t \mathrm{~N}, p s a \mathrm{I}, p s b \mathrm{~J}, p e t \mathrm{G}, r p o \mathrm{~A}, r p s 8$, $r p s 11, r p l 22, r p s 19, y c f 1, n d h \mathrm{~F})$ positioned at the single copy regions exhibit higher Pi values $(>0.005)$ (Figure 7A). On the other hand, the Pi values of the non-coding regions range from 0 to 0.03629 , with an average of 0.00798 . Among these regions, 10 regions (start- $p s b \mathrm{~A}, r p s 16 \mathrm{CDS1}-p s b \mathrm{~K}, p s b \mathrm{~K}-p s b \mathrm{I}, p s b \mathrm{I}-a t p \mathrm{~A}$, cemA-petA, petD CDS2-rpoA, ndhF-rpl32, rpl32-ccsA, ndhE-ndhG, ndhI-ndhA CDS2) have high diversity values ( $>0.012$ ) (Figure 7B). Most of these divergence hotspots are located in the LSC and SSC regions, signifying that IR regions are less variable. These results also exemplify that most hypervariable regions shown in the mVISTA alignment have higher nucleotide diversity $(\mathrm{Pi})$ values as well. 

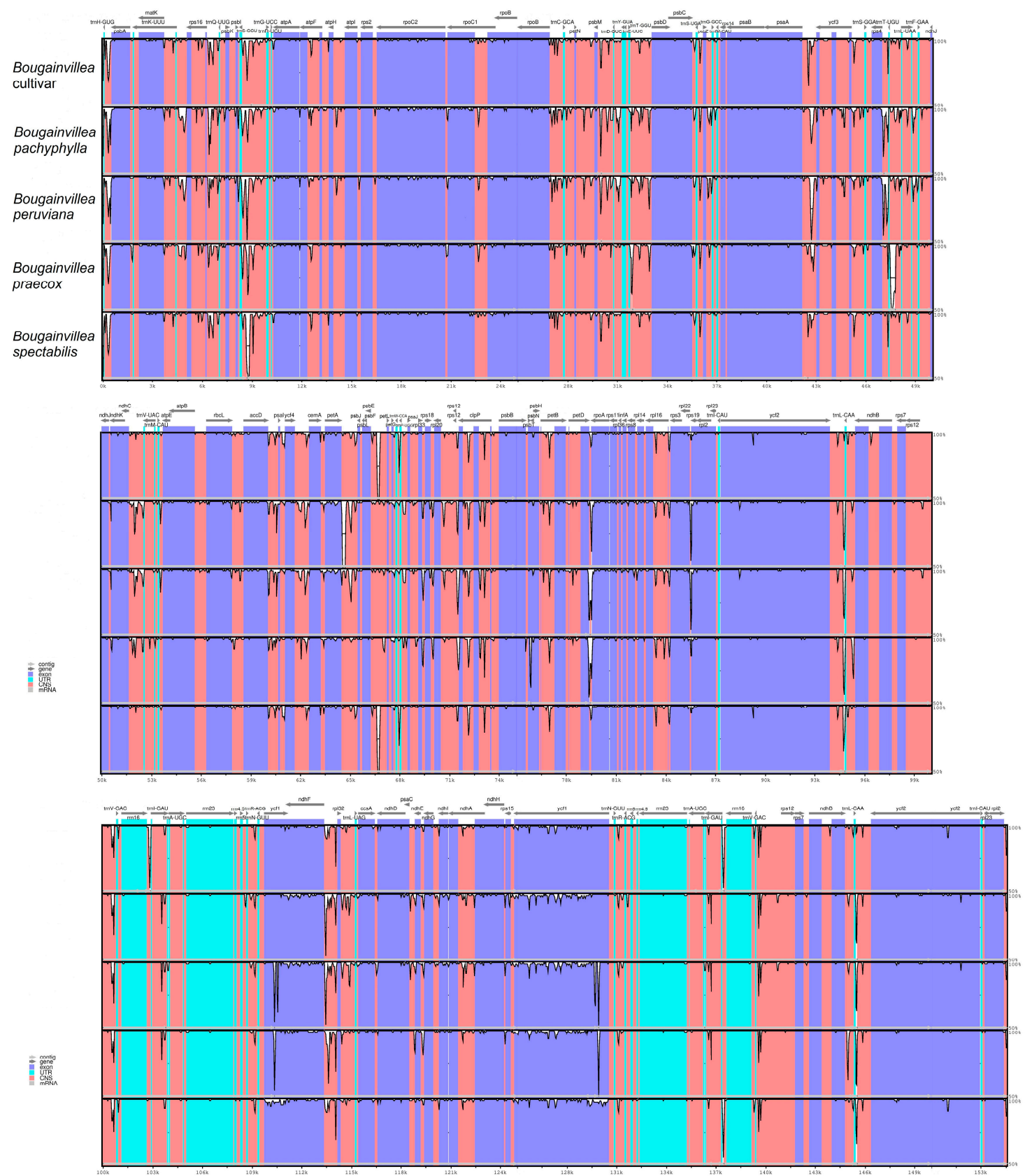

Figure 6. Sequence identity plots (mVISTA) among Bougainvillea species. Alignments of the five Bougainvillea plastomes, with Bougainvillea glabra as the reference genome. Genes are color-coded, whereby pink regions represent conserved non-coding sequences (CNS) and purple regions indicate protein-coding sequences. Grey arrows above the alignments indicate gene directions. The y-axis denotes the percentages of identity, ranging between $50 \%$ and $100 \%$.

The overall variation among the Bougainvillea sequences was analyzed through mVISTA and DnaSP v5.10, however to further elucidate the differences among taxa, SNP/indel analysis was also conducted using MUMmer 4 and Geneious 2020.2. Using Bougainvillea glabra as a reference, the single-nucleotide polymorphisms (SNPs) and indels (insertions deletions) were identified in the other five Bougainvillea cp genomes. General results revealed that more SNPs and indels were detected in B. pachyphylla and B. peruviana in contrast to the other three plastomes. When aligned to B. glabra, B. pachyphylla has 571 SNPs in the non-coding regions and 317 SNPs in the coding regions, whilst B. peruviana has 545 SNPs in the non-coding regions and 320 SNPs coding regions (Figure 8A). 
Lesser SNPs were found in B. praecox $(309,200)$, B. spectabilis $(283,195)$, and B. cultivar $(282,163)$, indicating that these three have higher sequence similarities to B. glabra (Figure $8 \mathrm{~A}$ ). There are also around $45-58$ protein-coding regions with SNPs; specifically, $y c f 1$, $n d h \mathrm{~F}, r p o \mathrm{C} 2$, and $r p o \mathrm{C} 1$ have higher numbers of SNPs (Figure 8B, Table S3). In all Bougainvillea, the ycf1 gene has the highest numbers of both synonymous and non-synonymous SNPs. The RNA polymerase genes $(r p o \mathrm{~A}, r p o \mathrm{~B}, r p o \mathrm{C} 2$, $r p o \mathrm{C} 1$ ), particularly rpo $\mathrm{C} 1$ and $r p o \mathrm{C} 2$, predominantly contain synonymous and non-synonymous SNPs (Table S3). Similar to the mVISTA alignment and nuclear diversity analyses, $y c f 1$ and $n d h \mathrm{~F}$ are also considered highly variable due to their high numbers of SNPs.

A

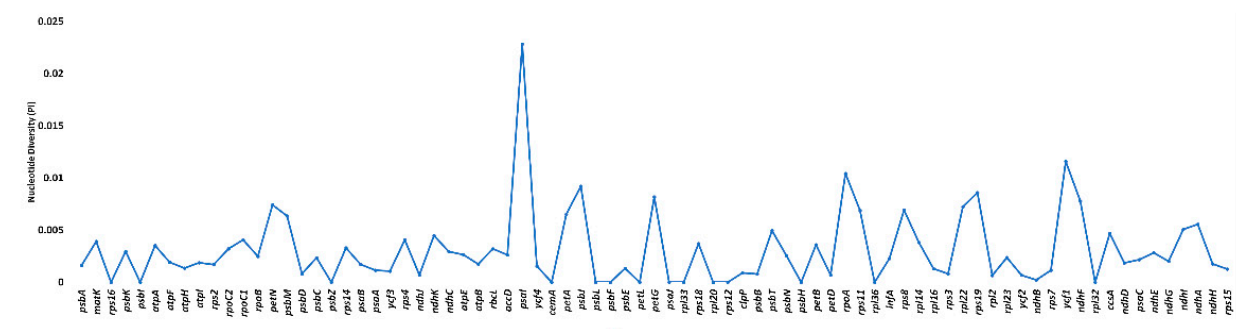

B

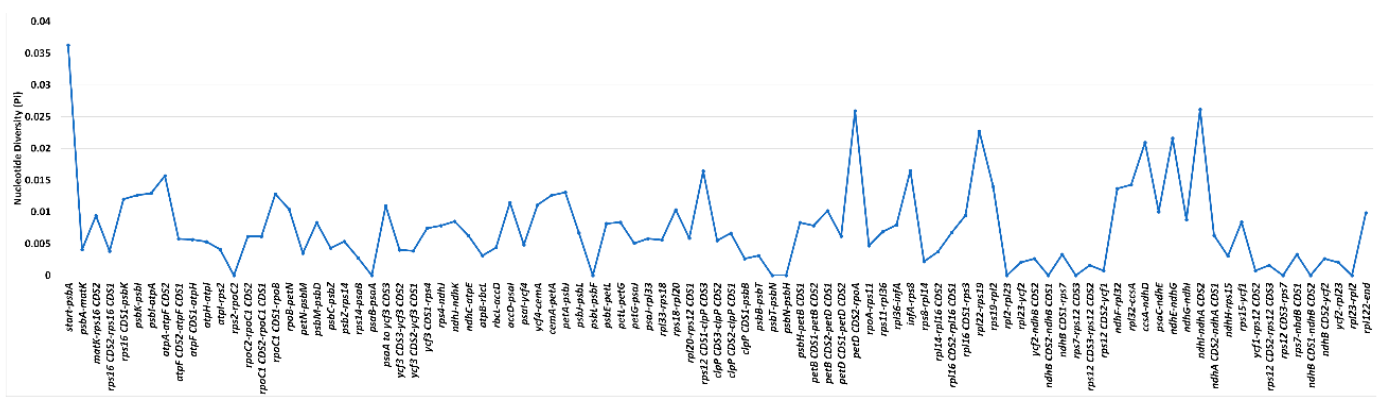

Figure 7. Nucleotide diversity (Pi) of various regions in Bougainvillea chloroplast genomes. (A) Nucleotide diversity values in the protein-coding regions. (B) Nucleotide diversity values in the non-coding regions.

A

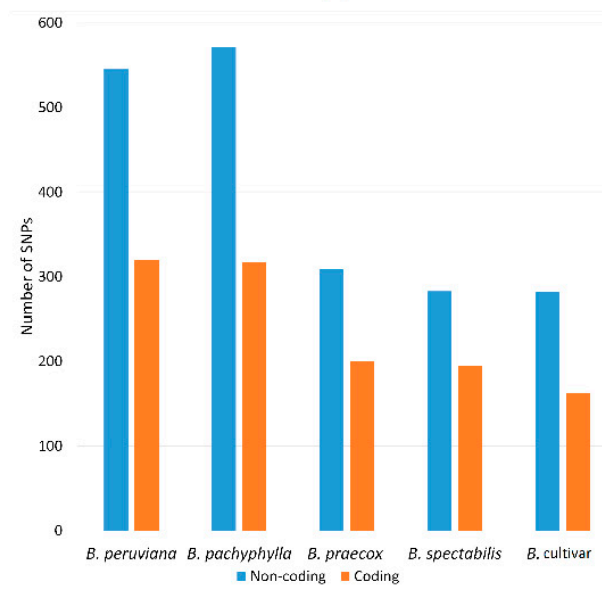

B

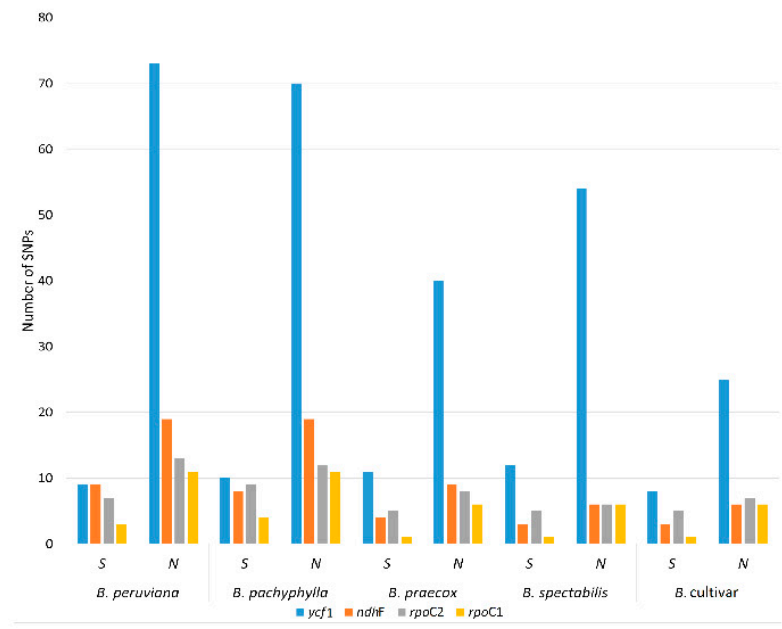

Figure 8. Summary of SNPs detected in the five Bougainvillea chloroplast genomes. (A) Frequency of SNPs in the coding and non-coding regions. (B) Protein-coding genes with highest numbers of synonymous and non-synonymous SNPs.

A similar trend can be observed in Bougainvillea indels, B. peruviana (366), and B. pachyphylla (357), which have more indels in comparison to B. praecox (218), B. spectabilis (171), and B. cultivar (171) (Figure 9A). Both B. spectabilis and B. cultivar have lesser indels, indicating less differences from 
B. glabra. The presence of the large deletion in the $c l p \mathrm{P}$ intron of B. spectabilis ( $55 \mathrm{bp})$, B. cultivar ( $55 \mathrm{bp}$ ), B. pachyphylla ( $47 \mathrm{bp}$ ), and B. peruviana ( $29 \mathrm{bp}$ ) mainly differentiates these four from B. glabra (Figure $\mathrm{S} 1$ ). On the other hand, both B. peruviana and B. pachyphylla differ from B. glabra by having a 43 bp deletion in the spacer in between rpl22 and rps19 (Figure S2). Although small indels are quite common in all Bougainvillea cp genomes, more one-bp indels (116) are discovered in B. peruviana and B. pachyphylla (Figure 9C). The presence of copious amounts of small indels and several large indels results in high sequence variation in B. peruviana and B. pachyphylla (Figure 9A,C). In addition, the majority of the indels detected in the five cp genomes are in the non-coding regions-only $y c f 1, y c f 2, c e m \mathrm{~A}, n d h \mathrm{~K}$, $n d h \mathrm{D}, r p o \mathrm{~A}, p s b \mathrm{~N}$, and $r p s 15$ have indels (Figure $9 \mathrm{~B}$ ). Again, $y c f 1$ and one of the RNA polymerase genes $(r p o A)$ exhibit a high degree of variation due to the presence of indels.
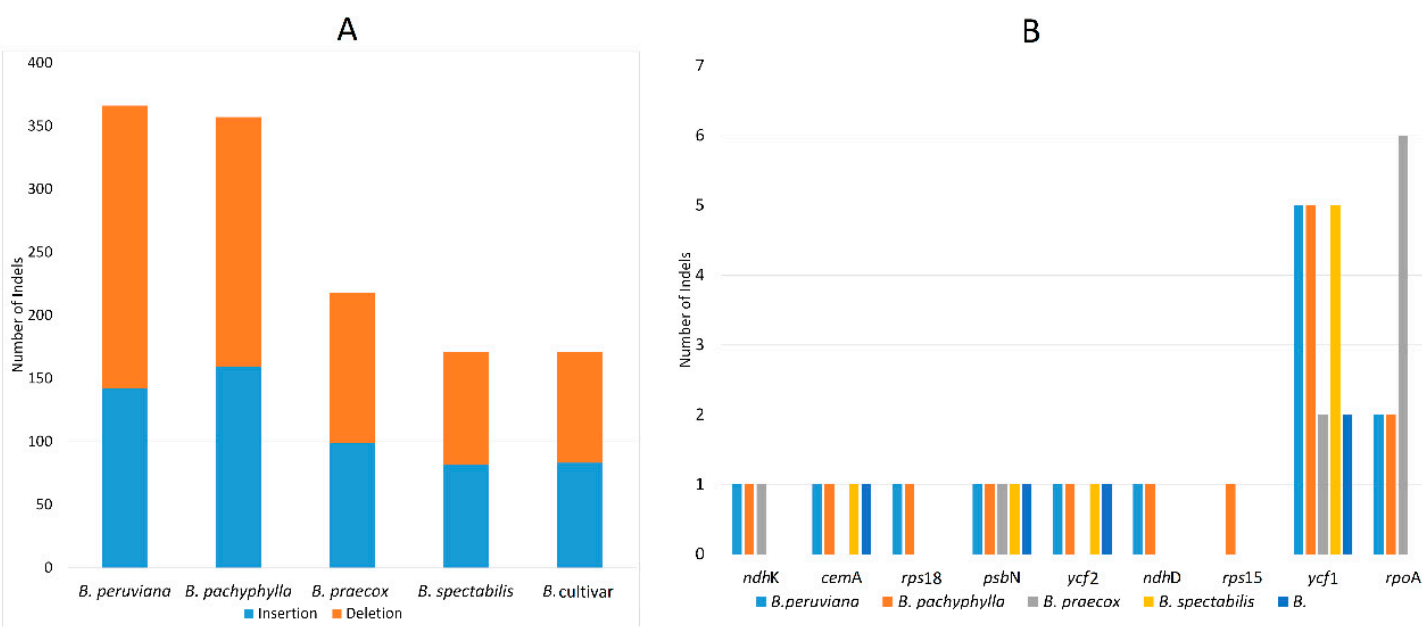

C

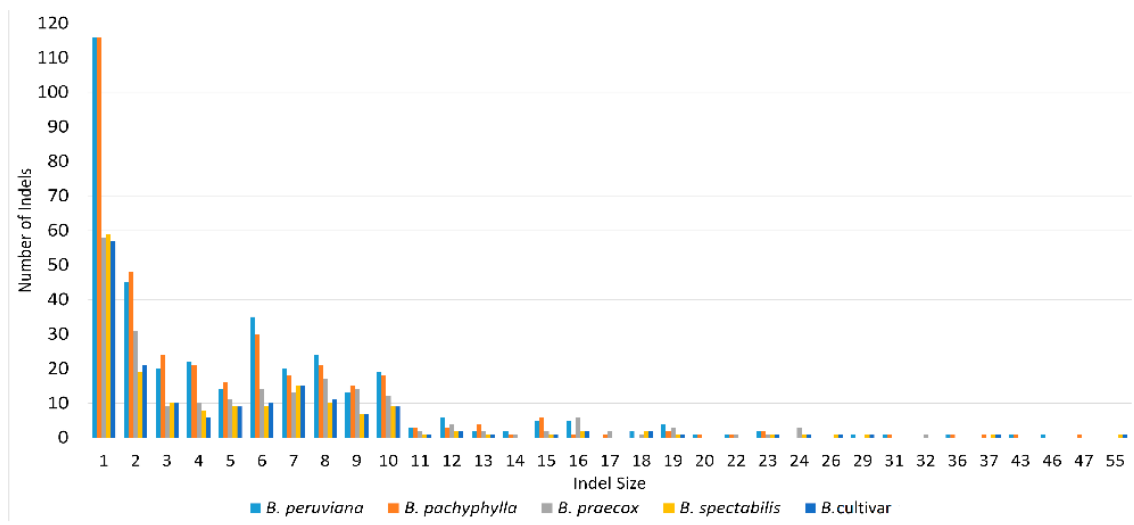

Figure 9. Summary of insertions and deletions found in five Bougainvillea cp genomes. (A) Total number of indels in five Bougainvillea species. (B) Numbers of indels located in the protein-coding genes. (C) Lengths of indels identified in five cp genomes.

Consolidating the results from various analyses, regions such as $y c f 1, n d h \mathrm{~F}$, and $r p o \mathrm{~A}$ are potential molecular markers. Consistent with all analyses, $y c f 1$ has high sequence divergence, high diversity value, and has the most SNPs and indels (Figure 6, Figure 7A, Figure 8B, and Figure 9B). Another good barcode candidate is the $n d h \mathrm{~F}$ gene, which displays high sequence divergence, high Pi value, and high SNP density (Figure 6, Figure 7A, and Figure 8B). Likewise, the nucleotide diversity analysis also showed that rpoA is considered a variable region (Figure 7A). Additionally, it also has good amounts of detected SNPs and indels (Table S2, Figure 9B). Therefore, to check whether these regions can actually differentiate Bougainvillea species, phylogenetic analyses was also conducted and compared to the phylogenetic tree inferred from all the protein-coding regions in Bougainvillea cp genomes. 


\subsection{Phylogenetic Analysis}

Several of the phylogenetic reconstructions focusing on the Nyctaginaceae family were based on a single gene or a few gene regions from plastid or nuclear DNA $[15,46]$, but none of them explicitly discussed the relationships among species of Bougainvillea. With the advent of next-generation sequencing, several cultivated Bougainvillea spectabilis and Bougainvillea glabra genomes have been published, but due to the lack of other available sequences, phylogenetic analyses have focused only on Bougainvillea's placement within the Nyctaginaceae family $[17,18]$. Thus, in this study, the phylogeny of Bougainvillea was reconstructed using eight complete chloroplast genomes of Bougainvillea (including the sequences from GenBank) and six other species from the Nyctaginaceae family. Species from Petiveriaceae were used as outgroups. In addition, the highly variable regions from the same dataset were extracted and used to construct a phylogenetic tree. As a whole, the resulting ML and BI trees based on complete cp genomes have a consistent and well-supported topology (Figure 10). Likewise, a similar topology was observed for the ML tree generated from the potential markers obtained from the sequence variation analyses (Figure S3).

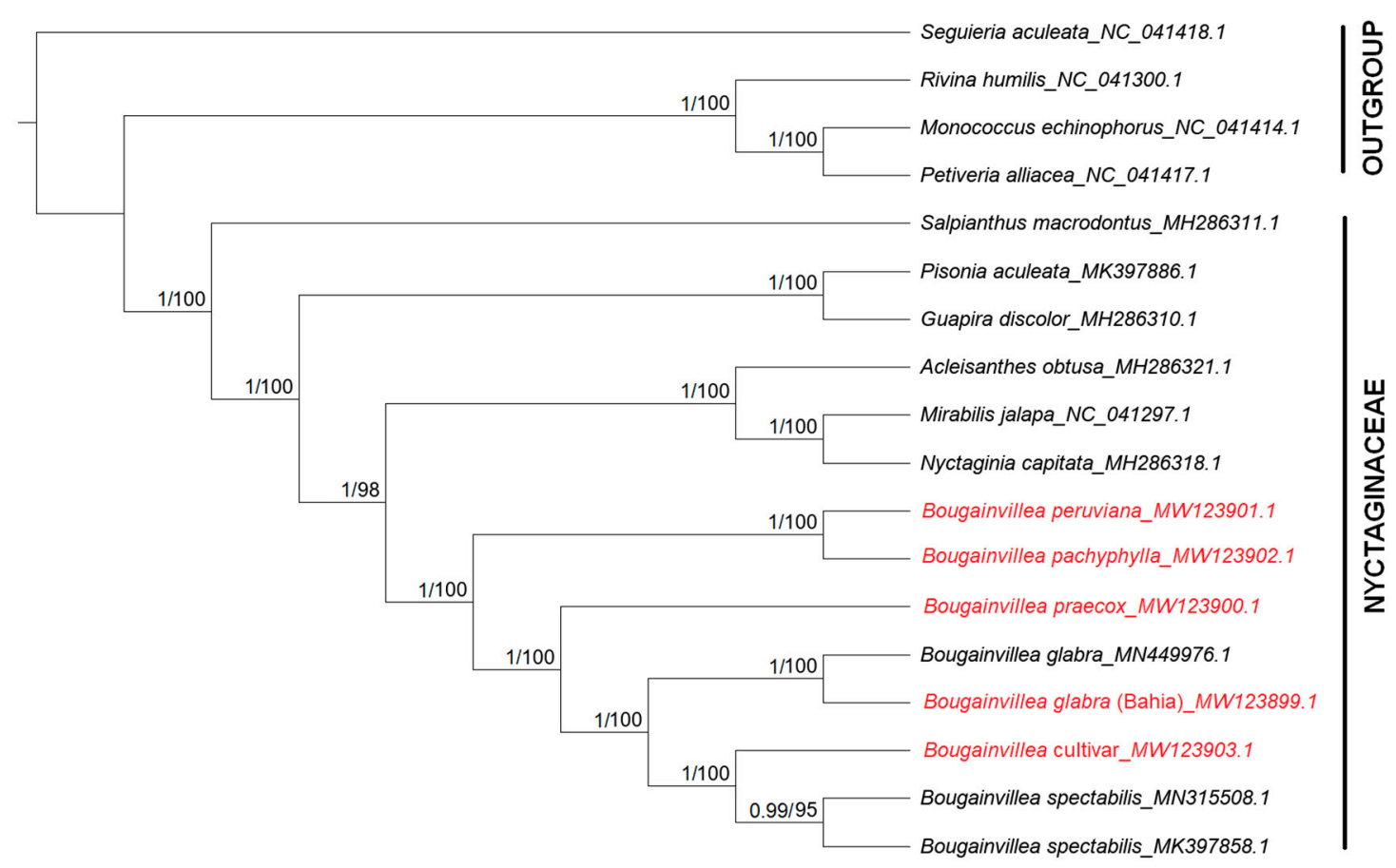

Figure 10. Maximum Likelihood (ML) and Bayesian Inference (BI) consensus tree based on the 79 concatenated protein-coding regions of 14 Nyctaginaceae cp genomes. Species from Petiveriaceae were used as outgroups. Numbers on each node represent bootstrap support and Bayesian posterior probability (BPP) values. Branches with bootstrap values $>75$ and BPP values $>95$ are considered as highly supported.

Bougainvilleeae, as represented by the Bougainvillea species, has higher affinity to the Nyctagineae tribe (Acleisanthes, Mirabilis, Nyctaginia) compared to other tribes within Nyctaginaceae. Within the Bougainvillea genus, Bougainvillea peruviana and Bougainvillea pachyphylla appear to be the basal taxa, while Bougainvillea praecox is a sister to two distinct subclades: the "glabra" and "spectabilis" subclades.

Based on its morphology, B. peruviana was assumed to be closely related to either B. glabra [12,47] or B. pachyphylla [48], but molecular data from cp genomes revealed that it has a closer relationship to B. pachyphylla. The sequence variation analysis discussed earlier also showed that B. peruviana and B. pachyphylla are the two genomes that differ most from B. glabra. In terms of morphological structure, B. pachyphylla is not too distinct from B. peruviana-it differs only by having thick and leathery leaves and a densely puberulent perianth in comparison to B. peruviana $[48,49]$. B. peruviana is considered one 
of the most sTable Species, as there is less variation in the shapes of the bracts and leaves [4]. This species is also not as vigorous as the cultivars and hybrids [4]. Therefore, the striking morphological and molecular similarities of $B$. pachyphylla to B. peruviana must be taken into consideration in future taxonomic revisions for the genus Bougainvillea.

On the other hand, Bougainvillea praecox is actually distinct from other Bougainvillea by being sparsely spiny or unarmed [12]. It is not usually used for cultivation, but it has showy white bracts that become greenish when dried. Based on the tree, B. praecox is the sister to two distinct groups containing Bougainvillea glabra and Bougainvillea spectabilis.

The close relationship between Bougainvillea glabra and Bougainvillea spectabilis is not surprising, as morphologically B. glabra is highly similar to B. spectabilis [10]. B. glabra differs only by having puberulent to glabrate branches and leaves, while B. spectabilis has fulvous-villous branches and densely villous abaxial leaf surfaces $[12,49]$. In addition, horticulturists have observed that $B$. spectabilis has stouter spines and wavy bracts. The sequences from GenBank are mostly cultivated and are either classified as B. glabra or B. spectabilis. Similarly, the Bougainvillea cultivar clusters together with B. spectabilis and B. glabra, since most of the cultivars are actually crosses between B. spectabilis and B. glabra. Many crosses between the two species have produced new hybrids and horticultural cultivars. As presented earlier, less sequence variation was observed among these three species, so closer relationships are also evident in the resulting trees.

In general, it can be observed that rarely cultivated and wild species of Bougainvillea (B. pachyphylla, B. peruviana, B. praecox) diverged earlier than the commonly cultivated species of Bougainvillea. These results showed that information inferred from highly variable regions and complete cp genome sequences resulted in consistent phylogeny. The potential barcodes can also successfully differentiate Bougainvillea species and cultivars, meaning more samples can be sequenced to give a broader view of the evolutionary relationships within this genus.

\section{Materials and Methods}

\subsection{Plant Samples and DNA Extraction}

The leaf samples of the four Bougainvillea species and one cultivar used in this study were collected from Brazil, Peru, Ecuador, and China. Two samples were obtained from Brazil, namely Bougainvillea glabra (M.B.M. da Cruz 0001 NY) from Ilhéus, Bahia; and Bougainvillea praecox (Chen T. 2012063001 SZG) from Jardim Botanico Plantarum, Nova Odes. Bougainvillea pachyphylla (Sagastegui A. et al. 15924 MO) was from Chota, Cajamarca, Peru, while Bougainvillea peruviana (Chen T. et al. 2014052606 SZG) was collected on the way from Loja to Macara, Ecuador. Lastly, the Bougainvillea cultivar (Chen T. 2020031204 SZG), which is originally from India, was acquired from Fairy Lake Botanical Garden, Shenzhen, China. Fresh leaves of B. glabra, B. praecox, B. peruviana, and B. cultivar were dried in silica gel, while the B. pachyphylla leaf sample was obtained from herbarium material. Total genomic DNA was extracted from each sample through the modified CTAB (cetyl trimethylammonium bromide) method [50], then the DNA quality was checked through agarose gel electrophoresis, nanodrop method, and Qubit 2.0.

\subsection{Chloroplast Genome Sequencing, Assembly, and Annotation}

After the DNA quality assessment, DNA was sheared to fragments using a Covaris ultrasonic disruptor. Short-insert (350-400 bp) libraries were constructed using the Nextera XT DNA Library Preparation Kit. Sequencing was performed in Illumina Novseq 600 platform, and for each sample around $10.0 \mathrm{~Gb}$ of raw data were generated, with an average read length of $150 \mathrm{bp}$ and sequencing depths of 263.8X-1627.3X. The Illumina raw sequence reads were filtered for adaptor sequences, undersized inserts, duplicated reads, and low-quality reads using the NGS-QC (Next Generation Sequencing Quality Control) toolkit [51]. High-quality reads were assembled into contigs via the de novo assembler SPAdes 3.11.0, using a k-mer set of 93, 105, 117, 121 [52]. 
The assembled Bougainvillea cp genomes were annotated using Plann software [53] and the online annotation tools cpGAVAS [54] and DOGMA [55]. Protein-coding gene annotation was also verified by BlastN searches of the non-redundant database at the National Center for Biotechnology Information (NCBI). RNAmmer 1.2 [56] and tRNAscan-SE v2.0 [57] were used to annotate rRNA and tRNA genes, respectively. The genome maps of the Bougainvillea $\mathrm{cp}$ genomes were generated using the online program OGDRAW v1.3.1 [58], then the cp genome sequences were deposited in National Center for Biotechnology Information (NCBI) GenBank with the accession numbers MW123899-MW123903.

\subsection{Codon Usage and RNA Editing Sites Prediction}

Relative synonymous codon usage (RSCU) was determined for all protein-coding genes using MEGAX software [59]. Amino acid frequency values were also obtained from MEGA X [59] and manually verified. In addition, probable RNA editing sites in six Bougainvillea cp genomes were identified using Predictive RNA Editor for Plants (PREP) suite (http://prep.unl.edu/), with a cutoff value of 0.8 [60]. The default settings (35 coding sequences) were used to predict putative RNA editing sites.

\subsection{Repeat Analysis}

Simple sequence repeats (SSRs) in the Bougainvillea cp genomes were identified using MISA (http://pgrc.ipk-gatersleben.de/misa/) [61], with motif sizes of one to six nucleotides and thresholds of $10,5,5,3,3$, and 3. Similar parameters had been used in other angiosperm cp genomes. Aside from SSRs, tandem repeats were also analyzed with the aid of Tandem Repeats Finder Program v4.04 [62] using default parameters. All identified repeats were manually filtered and redundant results were excluded. For tandem repeats, repeats with more than $90 \%$ sequence identity were included.

\subsection{Genome Comparison and Divergence Analyses}

The five newly sequenced Bougainvillea $\mathrm{cp}$ genomes were compared to the available cpDNA sequence of Bougainvillea spectabilis. For comparison, sequence alignment was carried out in mVISTA (http://genome.lbl.gov/vista/mvista/about.shtml) using Shuffle-LAGAN mode [63]. Bougainvillea glabra was used as the reference. In addition, the nucleotide diversity (Pi) values of the cp genomes were determined to detect various divergence hotspots. Using MAFFT v7.388 [64], Bougainvillea cp sequences were aligned, then DnaSP v5.10 [65] was utilized to compute the nucleotide diversity (Pi) values. Sliding window analysis was used, with a window length of $600 \mathrm{bp}$ and step size of $200 \mathrm{bp}$. The expansions and contractions in the IR junctions were also depicted using the online tool IRscope (https://irscope.shinyapps.io/irapp/) [66]. To further examine variations among the Bougainvillea cp genomes, SNPs and indels were also identified and located using MUMmmer 4 [67] and Geneious Prime 2020.2 [68]. The Bougainvillea glabra cp genome was also used as the reference.

\subsection{Phylogenetic Analyses}

Together with the five newly sequenced Bougainvillea cp genomes, three available Bougainvillea sequences and six Nyctaginaceae sequences deposited in NCBI GenBank were included in the dataset. Four complete cp genomes from the closely related family Petiveriaceae were used as outgroups. From these sequences, 79 protein-coding regions were extracted using Geneious Prime 2020.2. Multiple alignments of these extracted regions were conducted in MAFFT v7.388 [64]. Ambiguous regions in the alignments were manually removed, then the filtered alignments were concatenated using Geneious Prime 2020.2 [68], which generated a final alignment of 66,426 bp. Aside from the 79 concatenated protein-coding regions, sequenced alignment was also conducted in the selected highly divergent regions to test their barcode effectivity. The genes $n d h \mathrm{~F}, r p o \mathrm{~A}$, and $y c f 1$ were extracted and concatenated using Geneious Prime 2020.2 [68]

Maximum likelihood (ML) analyses were performed using RAxML 8.2.11 [69] and IQ-TREE v6.10 [70] with the GTR+I+G (General Time Reversible + Invariable Sites + Gamma Distribution) nucleotide substitution model. The best fit model was determined through jModelTest2, executed in 
CIPRES Gateway [71]. The bootstrap consensus tree was inferred from 1000 replicates. Furthermore, Bayesian inference tests were also conducted in MrBayes 3.2.6 [72] with the general time reversible (GTR) DNA substitution model and the gamma distribution rate variation across sites. Bayesian Inference analyses were carried out in CIPRES Gateway [71], with four Markov chain Monte Carlo (MCMC) running for one million generations, with sampling every 1000 generations and the first $25 \%$ being discarded as burn-in. The resulting branches with bootstrap support $>75 \%$ for maximum likelihood and Bayesian posterior probabilities (BPP) $>0.95$ for BI were considered as significantly supported.

\section{Conclusions}

Bougainvillea is deemed to be one of the most popular genera in the Nyctaginaceae family, as it is used mainly as an ornamental plant. However, despite its horticultural value, its molecular and phylogenetic aspects are not well-researched. Hence, in this paper, the complete chloroplast genomes of four species (B. glabra, B. peruviana, B. pachyphylla, B. praecox) and one cultivar were sequenced and analyzed. In general, all Bougainvillea cp genomes newly sequenced from GenBank, including Bougainvillea spectabilis, have similar genome structures and features. They all display the typical quadripartite structure and have the same numbers of genes (131) and introns (17). Highly similar patterns were also obtained from codon usage, RNA editing, and repeat analyses. Although the Bougainvillea cp genomes are highly conserved and no rearrangement was observed, several highly divergent regions were identified. Moreover, phylogenetic analyses revealed the early divergence of the rarely cultivated or wild Bougainvillea (B. peruviana, B. pachyphylla, B. praecox). B. pachyphylla and B. peruviana were shown to be the basal taxa of Bougainvillea. Close relationships among Bougainvillea glabra, Bougainvillea spectabilis, and Bougainvillea cultivar were also confirmed. These results show that chloroplast genomes can provide sufficient information that can be used in phylogenetic studies. However, more cp genome sequences are needed to further elucidate relationships among Bougainvillea species and cultivars.

Supplementary Materials: The following are available online at http://www.mdpi.com/2223-7747/9/12/1671/s1: Table S1: Codon usage. Table S2: RNA editing sites. Table S3: List of synonymous and non-synonymous SNPs. Figure S1: Large deletions in clpP introns of Bougainvillea cp genomes. Figure S2: Large deletions in Bougainvillea peruviana and Bougainvillea pachyphylla. Figure S3: Maximum likelihood tree based on potential Bougainvillea barcodes.

Author Contributions: All analyses, M.A.C.B.; writing of the manuscript and preparation of figures, tables, and graphs, M.A.C.B.; manuscript revision, M.A.C.B. and T.C.; conceptualization, planning, and supervision, T.C. and Y.D.; sample collection, T.C. and Y.Z.; resources and funding acquisition, T.C. and Z.H. All authors have read and agreed to the published version of the manuscript.

Funding: This work was supported by Shenzhen Urban Management Bureau (Chen, 2009); Shenzhen Science and Technology Basic Research Plan (JCYJ20120615172425764); the Fourth National Survey of Chinese Traditional Medicine Resources (GZY-KJS-2018-004); Shenzhen Key Laboratory of South Subtropical Plant Diversity, Fairy Lake Botanical Garden, Chinese Academy of Sciences (Chen, 2018-2020); and Key Laboratory of Plant Resource Conservation and Sustainable Utilization, South China Botanical Garden, Chinese Academy of Sciences (Deng, 2018-2020).

Acknowledgments: The authors would like to show sincere gratitude to Aimee Caye G. Chang and Sadaf Adnan for providing valuable suggestions related to the analyses; and to Nora Oleas of Technological University Indoamerica and Harri Lorenzi of the Jardim Botânico Plantarum for their kind assistance in the sample collection.

Conflicts of Interest: The authors declare no conflict of interest.

\section{References}

1. Mabberley, D.J. The Plant Book; Cambridge Univercity Press: Cambridge, UK, 1987; pp. 1-706.

2. Bittrich, V.; Kühn, U. Nyctaginaceae. In The Families and Genera of Flowering Plants; Kubitzki, K., Rohwer, J.G., Bittrich, V., Eds.; Springer: Berlin, Germany, 1993; Volume 2, pp. 473-486.

3. Bremer, B.; Bremer, K.; Chase, M.W.; Fay, M.F.; Reveal, J.L.; Soltis, D.E.; Soltis, P.S.; Stevens, P.F.; Anderberg, A.A.; Moore, M.J.; et al. An update of the Angiosperm Phylogeny Group classification for the orders and families of flowering plants: APG II. Bot. J. Linn. Soc. 2003, 141, 399-436. 
4. Kobayashi, K.D.; McConnell, J.; Griffis, J. Bougainvillea. In Ornamentals and Flowers; College of Tropical Agriculture and Human Resources, University of Hawaii: Honolulu, HI, USA, 2007; Volume OF-38, pp. 1-12.

5. Plants of the World Online. Facilitated by the Royal Botanic Gardens, Kew. Available online: http: //www.plantsoftheworldonline.org/ (accessed on 10 October 2020).

6. Kulshreshtha, K.; Rai, A.; Mohanty, C.S.; Roy, R.K.; Sharma, S.C. Particulate pollution mitigating ability of some plant species. Int. J. Environ. Res. 2009, 3, 137-142.

7. Chauhan, P.; Mahajan, S.; Kulshrestha, A.; Shrivastava, S.; Sharma, B.; Goswamy, H.M.; Prasad, G.B.K.S. Bougainvillea spectabilis Exhibits Antihyperglycemic and Antioxidant Activities in Experimental Diabetes. J. Evid. Based Complementary Altern. Med. 2016, 21, 177-185. [CrossRef] [PubMed]

8. Abarca-Vargas, R.; Petricevich, V.L. Bougainvillea Genus: A Review on Phytochemistry, Pharmacology, and Toxicology. J. Evid. Based Complementary Altern. Med. 2018, 2018, 9070927. [CrossRef]

9. Ogunwande, I.A.; Avoseh, O.N.; Olasunkanmi, K.N.; Lawal, O.A.; Ascrizzi, R.; Guido, F. Chemical composition, anti-nociceptive and anti-inflammatory activities of essential oil of Bougainvillea glabra. J. Ethnopharmacol. 2019, 232, 188-192. [CrossRef]

10. Abarca-Vargas, R.; Petricevich, V.L. Extract from Bougainvillea $\times$ buttiana (Variety Orange) Inhibits Production of LPS-Induced Inflammatory Mediators in Macrophages and Exerts a Protective Effect In Vivo. Biomed. Res. Int. 2019, 2019, 2034247. [CrossRef]

11. Rauf, M.A.; Oves, M.; Rehman, F.U.; Khan, A.R.; Husain, N. Bougainvillea flower extract me.diated zinc oxide's nanomaterials for antimicrobial and anticancer activity. Biomed. Pharmacother. 2019, 116, 108983. [CrossRef]

12. Standley, P.C. The Nyctaginaceae and Chenopodiaceae of Northwestern South America; Field Museum of Natural History-Botanical Series: Chicago, IL, USA, 1931; Volume 11, pp. 73-114.

13. Heimerl, A. Nyctaginaceae. In Engler \& Prantl, Naturl. Pflanzenfam, 2nd ed.; W. Engelmann: Leipzig, Germany, 1934; Volume 4, pp. 86-134.

14. Toursarkissian, M. Las Nictaginaceas argentinas. Revista Museo Argentino de Ciencias Naturales Bernardino Rivadavia. Botanica 1975, 5, 1-83.

15. Douglas, N.A.; Manos, P.S. Molecular phylogeny of Nyctaginaceae: Taxonomy, biogeography and characters associated with a radiation of xerophytic genera in North America. Am. J. Bot. 2007, 94, 856-872. [CrossRef]

16. Yao, G.; Jin, J.J.; Lia, H.T.; Yanga, J.B.; Mandalad, V.S.; Croleyd, M.; Mostowd, R.; Douglas, N.A.; Chase, M.W.; Christenhuszg, M.J.M.; et al. Plastid phylogenomic insights into the evolution of Caryophyllales. Mol. Phylogenet. Evol. 2019, 134, 74-86. [CrossRef]

17. Ni, J.; Lee, S.Y.; Hu, X.; Wang, W.; Zhang, J.; Ruan, L.; Dai, S.; Liu, G. The complete chloroplast genome of a commercially exploited ornamental plant, Bougainvillea glabra (Caryophyllales: Nyctaginaceae). Mitochondrial DNA Part B 2019, 4, 3390-3391. [CrossRef]

18. Wang, N.; Qiu, M.Y.; Yang, Y.; Li, J.W.; Xou, X.X. Complete chloroplast genome sequence of Bougainvillea spectabilis (Nyctaginaceae). Mitochondrial DNA Part B 2019, 4, 4010-4011. [CrossRef]

19. Moore, M.J.; Soltis, P.S.; Bell, C.D.; Burleigh, J.G.; Soltis, D.E. Phylogenetic analysis of 83 plastid genes further resolves the early diversification of eudicots. Proc. Natl. Acad. Sci. USA 2010, 107, 4623-4628. [CrossRef]

20. Li, B.; Li, Y.; Cai, Q.; Lin, F.; Huang, P.; Zheng, Y. Development of chloroplast genomic resources for Akebia quinata (Lardizabalaceae). Conserv. Genet. Resour. 2016, 8, 447-449. [CrossRef]

21. Munyao, J.N.; Dong, X.; Yang, J.X.; Mbandi, E.M.; Wanga, V.O.; Oulo, M.A.; Saina, J.K.; Musili, P.M.; Hu, G.W. Complete Chloroplast Genomes of Chlorophytum comosum and Chlorophytum gallabatense: Genome Structures, Comparative and Phylogenetic Analysis. Plants 2020, 9, 296. [CrossRef] [PubMed]

22. Kwon, E.C.; Kim, J.H.; Kim, N.S. Comprehensive genomic analyses with 115 plastomes from algae to seed plants: Structure, gene contents, GC contents, and introns. Genes Genome 2020, 42, 553-570. [CrossRef] [PubMed]

23. Xu, J.; Feng, D.; Song, G.; Wei, X.; Chen, L.; Wu, X.; Li, X.; Zhu, Z. The first intron of rice EPSP synthase enhances expression of foreign gene. Sci. China Life Sci. 2003, 46, 561-569. [CrossRef]

24. Daniell, H.; Lin, C.; Yu, M.; Chang, W. Chloroplast genomes: Diversity, evolution, and applications in genetic engineering. Genome Biol. 2016, 17, 134. [CrossRef]

25. Vu, H.T.; Tran, N.; Nguyen, T.H.; Vu, Q.L.; Bui, M.H.; Le, M.T.; Le, L. Complete chloroplast genome of Pahiopedilum delenatii and phylogenetic relationships among Orchidaceae. Plants 2020, 9, 61. [CrossRef] 
26. Wu, C.S.; Chaw, S.M. Evolutionary stasis in Cycad plastomes and the first case of plastome GC-biased gene conversion. Genome Biol. Evol. 2015, 7, 2000-2009. [CrossRef]

27. Niu, Z.; Xue, Q.; Wang, H.; Xie, X.; Zhu, S.; Liu, W.; Ding, X. Mutational Biases and GC-Biased Gene Conversion AT to GC Content in the Plastomes of Dendrobium Genus. Int. J. Mol. Sci. 2017, 18, 2307.

28. Knill, T.; Reichelt, M.; Paetz, C.; Gershenzon, J.; Binder, S. Arabidopsis thaliana encodes a bacterial-type heterodimeric isopropylmalate isomerase involved in both Leu biosynthesis and the Met chain elongation pathway of glucosinolate formation. Plant Mol. Biol. 2009, 71, 227-239. [CrossRef]

29. Hildebrandt, T.M.; Nunes Nesi, A.; Araujo, W.L.; Braun, H.P. Amino Acid Catabolism in Plants. Mol. Plant. 2015, 8, 1563-1579. [CrossRef] [PubMed]

30. Marino, S.M.; Gladyshev, V.N. Analysis and functional prediction of reactive cysteine residues. J. Biol. Chem. 2012, 287, 4419-4425. [CrossRef] [PubMed]

31. Li, D.M.; Zhu, G.F.; Xu, Y.C.; Ye, Y.J.; Liu, J.M. Complete Chloroplast Genomes of Three Medicinal Alpinia Species: Genome Organization, Comparative Analyses and Phylogenetic Relationships in Family Zingiberaceae. Plants 2020, 9, 286. [CrossRef] [PubMed]

32. Wu, X.M.; Wu, S.F.; Ren, D.M.; Zhu, Y.P.; He, F.C. The analysis method and progress in the study of codon bias. Yi Chuan $=$ Hered. 2007, 29, 420-426. [CrossRef]

33. Zhou, Z.; Dang, Y.; Zhou, M.; Li, L.; Yu, C.H.; Fu, J.; Chen, S.; Liu, Y. Codon usage is an important determinant of gene expression levels largely through its effects on transcription. Proc. Natl. Acad. Sci. USA 2016, 113, E6117-E6125. [CrossRef]

34. Wang, Z.; Xu, B.; Li, B.; Zhou, Q.; Wang, G.; Jiang, X.; Wang, C.; Xu, Z. Comparative analysis of codon usage patterns in chloroplast genomes of six Euphorbiaceae species. PeerJ 2020, 8, e8251. [CrossRef]

35. Lee, S.R.; Kim, K.; Lee, B.Y.; Lim, C.E. Complete chloroplast genomes of all six Hosta species occurring in Korea: Molecular structures, comparative, and phylogenetic analyses. BMC Genom. 2019, 20, 833. [CrossRef]

36. He, P.; Huang, S.; Xiao, G.; Zhang, Y.; Yu, J. Abundant RNA editing sites of chloroplast protein-coding genes in Ginkgo biloba and an evolutionary pattern analysis. BMC Plant Biol. 2016, 16, 257. [CrossRef]

37. Sasaki, T.; Yukawa, Y.; Miyamoto, T.; Obokata, J.; Sugiura, M. Identification of RNA Editing Sites in Chloroplast Transcripts from the Maternal and Paternal Progenitors of Tobacco (Nicotiana tabacum): Comparative Analysis Shows the Involvement of Distinct Trans-Factors for ndhB Editing. Mol. Biol. Evol. 2003, 20, 1028-1035. [CrossRef] [PubMed]

38. Yura, K.; Go, M. Correlation between amino acid residues converted by RNA editing and functional residues in protein three-dimensional structures in plant organelles. BMC Plant Biol. 2008, 8, 79. [CrossRef] [PubMed]

39. Vieira, M.L.; Santini, L.; Diniz, A.L.; de Freitas Munhoz, C. Microsatellite markers: What they mean and why they are so useful. Genet. Mol. Biol. 2016, 39, 312-328. [CrossRef] [PubMed]

40. Ebert, D.; Peakall, R. Chloroplast simple sequence repeats (cpSSRs): Technical resources and recommendations for expanding cPSSR discovery and applications to a wide array of plant species. Mol. Ecol. Resour. 2009, 9, 673-690. [CrossRef] [PubMed]

41. Kumar, P.; Janakiram, T.; Bhat, K.V.; Jain, R.; Prasad, K.V.; Prabhu, K.V. Molecular characterization and cultivar identification in Bougainvillea spp. using SSR markers. Indian J. Agric. Sci. 2014, 84, 1024-1030.

42. Zhao, Z.; Guo, C.; Sutharzan, S.; Li, P.; Echt, C.S.; Zhang, J.; Liang, C. Genome-wide analysis of tandem repeats in plants and green algae. G3 (Bethesda) 2014, 4, 67-78. [CrossRef]

43. Verstrepen, K.J.; Jansen, A.; Lewitter, F.; Fink, G.R. Intragenic tandem repeats generate functional variability. Nat. Genet. 2005, 37, 986-990. [CrossRef]

44. Li, J.; Zhang, D.; Ouyang, K.; Chen, X. The complete chloroplast genome of the miracle tree Neolamarckia cadamba and its comparison in Rubiaceae family. Biotechnol. Biotechnol. Equip. 2018, 32, 1314-3530. [CrossRef]

45. Feng, S.; Zheng, K.; Jiao, K.; Cai, Y.; Chen, C.; Mao, Y.; Wang, L.; Zhan, X.; Ying, Q.; Wang, H. Complete chloroplast genomes of four Physalis species (Solanaceae): Lights into genome structure, comparative analysis, and phylogenetic relationships. BMC Genom. 2020, 20, 242. [CrossRef]

46. Douglas, N.; Spellenberg, R. A new tribal classification of Nyctaginaceae. Taxon 2010, 59, 905-910. [CrossRef]

47. Tripathi, S.; Singh, S.; Roy, R.K. Pollen morphology of Bougainvillea (Nyctaginaceae): A popular ornamental plant of tropical and sub-tropical gardens of the world. Rev. Palaeobot. Palynol. 2017, 239, 31-46. [CrossRef] 
48. Standley, P.C. Studies of American Plants; Field Museum of Natural History-Botanical Series: Chicago, IL, USA, 1931; Volume 8, pp. 44-48.

49. Standley, P.C. Nyctaginaceae. In Flora of Peru; Macbride, J.F., Ed.; Field Museum of Natural History-Botanical Series: Chicago, IL, USA, 1937; Volume 13, pp. 518-546.

50. Murray, M.G.; Thompson, W.F. Rapid isolation of high molecular weight plant DNA. Nucleic Acids Res. 1980, 8, 4321-4326. [CrossRef]

51. Patel, R.K.; Jain, M. NGS QC Toolkit: A toolkit for quality control of next generation sequencing data. PLOS ONE 2012, 7, e30619. [CrossRef]

52. Bankevich, A.; Nurk, S.; Antipov, D.; Gurevich, A.A.; Dvorkin, M.; Kulikov, A.S.; Lesin, V.M.; Nikolenko, S.I.; Pham, S.; Prjibelski, A.D.; et al. SPAdes: A new genome assembly algorithm and its applications to single-cell sequencing. J. Comput. Biol. 2012, 19, 455-477. [CrossRef]

53. Huang, D.I.; Cronk, Q. Plann: A command-line application for annotating plastome sequences. Appl. Plant Sci. 2015, 3, 1500026. [CrossRef]

54. Liu, C.; Shi, L.; Zhu, Y.; Chen, H.; Zhang, J.; Lin, X.; Guan, X. CpGAVAS, an integrated web server for the annotation, visualization, analysis, and GenBank submission of completely sequenced chloroplast genome sequences. BMC Genom. 2012, 13, 715. [CrossRef]

55. Wyman, S.K.; Jansen, R.K.; Boore, J.L. Automatic annotation of organellar genomes with DOGMA. Bioinformatics 2004, 20, 3252-3255. [CrossRef]

56. Lagesen, K.; Hallin, P.F.; Rodland, E.; Staerfeldt, H.H.; Rognes, T.; Ussery, D.W. RNAmmer: Consistent annotation of rRNA genes in genomic sequences. Nucleic Acids Res. 2007, 35, 3100-3108. [CrossRef]

57. Chan, P.P.; Lowe, T.M. tRNAscan-SE: Searching for tRNA genes in genomic sequences. Methods Mol. Biol. 2019, 1962, 1-14.

58. Greiner, S.; Lehwark, P.; Bock, R. OrganellarGenomeDRAW (OGDRAW) version 1.3.1: Expanded toolkit for the graphical visualization of organellar genomes. Nucleic Acids Res. 2019, 47, W59-W64. [CrossRef]

59. Kumar, S.; Stecher, G.; Li, M.; Knyaz, C.; Tamura, K. MEGA X: Molecular Evolutionary Genetics Analysis across computing platforms. Mol. Biol. Evol. 2018, 35, 1547-1549. [CrossRef] [PubMed]

60. Mower, J.P. The PREP suite: Predictive RNA editors for plant mitochondrial genes, chloroplast genes and user-defined alignments. Nucleic Acids Res. 2009, 37, W253-W259. [CrossRef] [PubMed]

61. Beier, S.; Thiel, T.; Münch, T.; Scholz, U.; Mascher, M. MISA-web: A web server for microsatellite prediction. Bioinformatics 2017, 33, 2583-2585. [CrossRef] [PubMed]

62. Benson, G. Tandem repeats finder: A program to analyze DNA sequences. Nucleic Acids Res. 1999, 27, 573-580. [CrossRef] [PubMed]

63. Frazer, K.A.; Pachter, L.; Poliakov, A.; Rubin, E.M.; Dubchak, I. VISTA: Computational tools for comparative genomics. Nucleic Acids Res 2004, 32, W273-W279. [CrossRef]

64. Katoh, K.; Standley, D.M. MAFFT multiple sequence alignment software version 7: Improvements in performance and usability. Mol. Biol. Evol. 2013, 30, 772-780. [CrossRef]

65. Librado, P.; Rozas, J. DnaSP v5: A software for comprehensive analysis of DNA polymorphism data. Bioinformatics 2009, 25, 1451-1452. [CrossRef]

66. Amiryousefi, A.; Hyvönen, J.; Poczai, P. IRscope: An online program to visualize the junction sites of chloroplast genomes. Bioinformatics 2018, 34, 3030-3031. [CrossRef]

67. Marcais, G.; Delcher, A.L.; Phillippy, A.M.; Coston, R.; Salzberg, S.L.; Zimin, A. MUMmer4: A fast and versatile genome alignment system. PLoS Comput. Biol. 2018, 14, e1005944. [CrossRef]

68. Kearse, M.; Moir, R.; Wilson, A.; Stones-Havas, S.; Cheung, M.; Sturrock, S.; Buxton, S.; Cooper, A.; Markowitz, S.; Duran, C.; et al. Geneious Basic: An integrated and extendable desktop software platform for the organization and analysis of sequence data. Bioinformatics 2012, 28, 1647-1649. [CrossRef]

69. Stamatakis, A. RAxML Version 8: A tool for phylogenetic analysis and post-analysis of large phylogenies. Bioinformatics 2014, 30, 1312-1313. [CrossRef] [PubMed]

70. Trifinopoulos, J.; Nguyen, L.T.; von Haeseler, A.; Minh, B.Q. W-IQ-TREE: A fast online phylogenetic tool for maximum likelihood analysis. Nucleic Acids Res. 2016, 44, W232-W235. [CrossRef] [PubMed]

71. Miller, M.A.; Pfeiffer, W.; Schwartz, T. Creating the CIPRES science gateway for inference of large phylogenetic trees. In Proceedings of the Gateway Computing Environments Workshop (GCE), New Orleans, LA, USA, 14 November 2010; pp. 1-8. 
72. Ronquist, F.; Huelsenbeck, J.P. MrBayes 3: Bayesian phylogenetic inference under mixed models. Bioinformatics 2003, 19, 1572-1574. [CrossRef] [PubMed]

Publisher's Note: MDPI stays neutral with regard to jurisdictional claims in published maps and institutional affiliations.

(C) 2020 by the authors. Licensee MDPI, Basel, Switzerland. This article is an open access article distributed under the terms and conditions of the Creative Commons Attribution (CC BY) license (http://creativecommons.org/licenses/by/4.0/). 